\title{
The Dark Side of Wage Indexed Pensions
}

\author{
Evert Carlsson and Karl Erlandzon ${ }^{1}$ \\ Centre for Finance $\&$ Department of Economics, Göteborg School of Business, Economics and Law, \\ PO Box 640, S-40530 Göteborg ${ }^{2}$
}

Version: 2005-09-23

This paper investigates some welfare effects of forced saving through a mandatory pension scheme. The framework for the analysis is a life-cycle model of a borrowing constrained individual's consumption and portfolio choice in the presence of uncertain labour income and realistically calibrated tax and pension systems. Pension benefits stem from both a defined benefit and a notionally defined contribution part, the latter being indexed to stochastic aggregate labour income. We show that agents attribute little value to their pension savings in early life. Furthermore, we estimate the welfare loss for individuals in mid-life associated with the dependency between pension returns and labour income growth to $1.2 \%$ in annual consumption.

Key Words: Life-cycle, portfolio choice, pensions.

JEL classification: D91, G11, G23

\footnotetext{
${ }^{1}$ We would like to thank Bjarne Astrup-Jensen, Wlodek Bursztyn, Lennart Flood, Fransisco Gomes, Lennart Hjalmarsson, Cătălin Stărică and participants at the CFF seminar for comments and discussions. The usual disclaimer applies. Carlsson and Erlandzon greatefully acknowledges the financial support of the Department of Economics and Centre For Finance. Erlandzon also greatefully acknowledges support from Stiftelsen Bankforskningsinstitutet.

2 e-mail address:evert.carlsson@cff.gu.se; tel:+46 317732556.
} 
Life-cycle models have generated a lot of interest as a tool for explaining the accumulation and distribution of wealth as well as portfolio choice over the life-cycle. For agents with uncertain income and liquidity constraints, savings serve several purposes, eg. precautionary, retirement and bequest. The importance of each of these motives varies over the life-cycle and will consequently affect both the consumption and the allocation between assets. Over the life-cycle, retirement savings will dominate in absolute size and are to a large extent accumulated in mandatory pension schemes. The introduction of such a scheme into a life-cycle model will motivate an optimising agent to respond by adjusting her consumption and portfolio composition over time. Furthermore, the design of the mandatory pension scheme will have important welfare effects.

This paper has its origin in the literature that highlights uncertainty and market incompleteness as important factors in explaining individual choice and welfare. The first papers on this subject came from the consumption literature on buffer-stock saving. The life-cycle / permanent income hypothesis of Modigliani and Brumberg (1954) and Friedman (1957), implies that there should be no correlation between consumption and predictable income change, since agents would borrow against future incomes as a mean to equalise consumption over life. However, data shows a positive correlation between the two ( $c f$. Flavin (1981), Hall and Mishkin (1982) and Zeldes (1989)).

Deaton (1991), Carroll (1997) and Gourinchas and Parker (2002) created life-cycle models with uncertain wage income and where human capital could not be used as collateral for borrowing and where saving was invested in a risk-free asset. These models could explain the positive correlation between consumption and predictable income change as a rational response to uninsurable income risk in the presence of borrowing constraints ${ }^{3}$.

Cocco et al. (2005) and others have extended these models by allowing the agents to allocate between risk-free and risky assets. In order to analyse the effects of different retirement savings systems, Campbell, Cocco, Gomes \& Maenhout (2001) (henceforth CCGM) augmented the Cocco et al. (2005) model by including a mandatory pension scheme. The authors also showed that a lower pension contribution has the effect that younger generations postpone their private savings to a time when their

\footnotetext{
${ }^{3}$ Deaton (1991) and Gourinchas and Parker (2002) impose borrowing constraints, while Carroll (1997) sets up a model where the agents choose never to borrow.
} 
labour incomes are higher and thereby increasing their welfare.

In this paper we want to analyse some welfare effects of forced saving through mandatory pensions schemes. Our model is set in partial equilibrium, whereas eg. Heaton and Lucas (2004) investigates equilibrium effects of alternative pension systems. We restrict our analysis to the problem of an individual, who disregards any societal consequences of her choice. The individual welfare effect from forced saving can originate from (at least) four sources. Firstly, it may increase pension savings above the unrestricted level, especially early in life when savings are driven primarily by precautionary motives. Secondly, wealth in retirement accounts cannot be used to accommodate negative income shocks and will therefore incentivise the individual to make additional savings as a precaution. Thirdly, the risk and return characteristics of the "pension asset" may differ from the optimal choice and finally it redistributes income from early to later in life, when different tax rates may apply. In order to analyse these effects, we have chosen a model similar to the life-cycle model of CCGM.

We model individuals rather than households. Our rationale is that: female labour participation and divorce rates are high, which together with an age difference between male and spouse can obscure the expected earnings profile if estimated on family data ${ }^{4}$ and consequently the "optimal" behaviour in terms of choices will be erroneous; pension contributions and benefits are often based on individual rather than family incomes; taxes are usually progressive and primarily dependent on the individual instead of family incomes.

We have chosen Sweden as a benchmark for the calibration of our model, due to the relative simplicity and transparency of both the $\operatorname{tax}^{5}$ and pension systems. After the Swedish pension reform in 1999, pension contributions are credited to an individual notional account with a return set to aggregate labour income growth. This reform has attracted a lot of interest as a potential blue print for other countries, (cf. Schieber \& Shoven (1996) and Diamond (2002)). Furthermore, both tax and pension systems are solely dependent on individual rather than a mixture of individual and family incomes. Finally, the availability of high quality register based data also alleviates some of the quality problems associated with survey data. While calibrated on Swedish data and rules for taxes

\footnotetext{
${ }^{4}$ When estimating on family data, the educational status, age and retirement date is typically defined by the head of household only.

${ }^{5}$ Most people can file their declaration of their income tax by sending a SMS or e-mail
} 
and pensions, there are several similarities to systems in other countries, eg. the US Social Security retirement system. In both Sweden and the US, contributions and benefits are dependent on gross individual income and most importantly, benefits are indexed by average wage growth.

Our model extends the CCGM model by including a realistically calibrated tax and pension system. The main contribution of this paper is that we can attribute a value to mandatory pension savings and analyse the welfare effects of pension returns linked to stochastic labour income growth. Our findings show that, young individuals saves primarily for precautionary motives and will therefore attribute little value to savings in retirement account. Furthermore, there is a loss of welfare associated with uncertain pension returns indexed by labour income growth. This loss stems primarily from the dependency between labour income and pension returns, rather than the volatility of pension returns.

The paper is organised as follows. Section 1 describes the model, while Section 2 demonstrates how the model is calibrated. The solution algorithm and results are presented in Section 3. Finally, we end with some concluding remarks in Section 4.

\section{THE MODEL}

\subsection{Individual preferences}

The individual (rather than household) maximises the expected utility over a finite life-cycle, which is divided into pre- and post-retirement. Each individual starts her "optimization life" at the age of 20 or 23 (the latter for those with a university degree) $\tau_{0}$, retires at 65 and dies at a maximum age of 100 $T$. Individuals have constant relative risk aversion preferences on a single non-durable consumption good.

Individual preferences at time $m$ are defined as

$$
\frac{C_{m}^{1-\gamma}}{1-\gamma}+E_{m} \sum_{\tau=m+1}^{T} \delta^{\tau-m}\left(\prod_{j=m}^{\tau-2} p_{j}\right)\left\{p_{\tau-1} \frac{C_{\tau}^{1-\gamma}}{1-\gamma}+b\left(1-p_{\tau-1}\right) \frac{D_{\tau}^{1-\gamma}}{1-\gamma}\right\}
$$

where $C_{\tau}$ represent consumption at age $\tau, \gamma$ is the coefficient of relative risk aversion, $p_{\tau}$ is the one year age contingent survival probability, $\delta$ is the discount factor, $b$ is the bequest parameter and $D_{\tau}$ 
is the bequest amount.

\subsection{Labour income}

The labour income process follows Carroll and Samwick (1997) with the exception that it is based on an individual rather than a household. Individuals were divided into six mutually exclusive groups with respect to sex and education. While in the labour force, the individual experiences idiosyncratic as well as common shocks to gross income. During the pre-retirement period the log labour real income $l_{i k \tau}$ for an individual $i$ belonging to group $k$ is exogenous and given $\operatorname{as}^{6}$

$$
l_{i k \tau}=f_{k}\left(\tau, \mathbf{Z}_{i k \tau}\right)+v_{i k \tau}+\epsilon_{i k \tau}
$$

where $f_{k}$ is a function of the individual characteristics ${ }^{7} \mathbf{Z}_{i k \tau}$ as well as an average national labour productivity growth $\mu^{l}, \epsilon_{i k \tau}$ is an idiosyncratic temporary shock distributed as $N\left(0, \sigma_{\varepsilon_{k}}\right)$ and $v_{i k \tau}$ is a random walk

$$
v_{i k \tau}=v_{i k \tau-1}+u_{i k \tau} \text {. }
$$

The innovation, $u_{i k \tau}$ is divided into a group aggregate $\xi_{k \tau} \sim N\left(0, \sigma_{\xi_{k}}\right)$ and an individual uncorrelated component $\omega_{i k \tau} \sim N\left(0, \sigma_{\omega_{k}}\right)$ as below

$$
u_{i k \tau}=\xi_{k \tau}+\omega_{i k \tau}
$$

\subsection{Mandatory savings and retirement benefits}

The Swedish mandatory pension system is divided into a notional defined contribution - NDC part and a funded defined contribution - FDC. Contributions are paid by the employer and are set to $18.5 \%$ of gross income, $16 \%$ is added to the $N D C$ account $^{8}$ and $2.5 \%$ to the $F D C, c f$. RFV (2002). In our portfolio choice model, each part of the pension system unfortunately requires a separate state

\footnotetext{
${ }^{6}$ Throughout this paper, we discriminate between the future time periods - $\tau$, which belongs to the optimization problem and the historic time - $t$, which is used for estimation.

${ }^{7}$ i.e. age, martial status, family size, number and age of children.

${ }^{8}$ In the US, benefits are funded through a Social Security tax of $12.4 \%$ on the employee's income up to an amount of $\$ 90,000$.
} 
variable, adding to the curse of dimensionality, cf. Bellman (1961). We therefore disregard the smaller $F D C$ part of this system.

Contributions to the national pension plan are capped above an income of $300 \mathrm{KSEK}^{9}$. The return on the national pension plan $R_{\tau}^{l}$ is set to the national labour income growth ${ }^{10}$

$$
\begin{gathered}
R_{\tau}^{l}=e^{\mu^{l}+\xi_{\tau}^{A}} \\
N D C_{i \tau}=\left\{\begin{array}{cc}
R_{\tau-1}^{l} \cdot N D C_{i \tau-1}+0.16 \min \left[L_{i \tau}, 300\right] & , \tau<65 \\
R_{\tau-1}^{l} \cdot N D C_{i \tau-1}-P O_{\tau}\left(R_{\tau-1}^{l} \cdot N D C_{i \tau-1}\right) & , \tau \geq 65,
\end{array}\right.
\end{gathered}
$$

where $P O_{\tau}$ is the age specific annualised mortality adjusted payout function after retirement and $\mu^{l}$ is the expected national labour income growth aggregated over all groups with noise, $\xi_{\tau}^{A} \sim N\left(0, \sigma_{\xi^{A}}\right)$.

Due to the cap on contributions to the $N D C$ plan, the employer partly compensates by paying into a negotiated plan with the individual as the beneficiary. Albeit varying to some degree, the vast majority of assets in such plans are managed similarly and at present as defined benefit plans, with benefits depending on the wage at retirement. These company defined benefit plans has a payout of $10 \%, 65 \%$ and $32.5 \%$ on incomes in the intervals $[0,320),[320,850)$, and $[850,1270)$ respectively at retirement. The return of the company plan is insured to pay a defined benefit depending on the wage at retirement and guaranteed for the remaining life with no real appreciation after retirement. In reality it depends on the wage during the last five years prior to retirement. However, modelling this rule correctly would have necessitated additional state variables. We therefore approximate this by only including the permanent changes in income up until retirement,

$$
L_{i 64}^{P}=e^{f_{k}\left(\tau, \mathbf{Z}_{i k 64}\right)+v_{i k 64}} .
$$

Payout from this plan during retirement will be denoted $D B P O_{i \tau}$ and its dynamics is given by

\footnotetext{
${ }^{9}$ In the following, the KSEK - thousands of Swedish Crowns will be omitted. The present exchange rate is cirka 7 SEK / USD.

${ }^{10}$ National Social Insurance Board (Riksförsäkringsverket) is responsible for the actuarial estimation of liabilities and the appropriate discount rate. In reality, if the assets in terms of estimated future contributions and return from the buffer funds does not support the growth of liabilities, then the actual benefits paid out will be reduced until the assets match the liabilities and vice versa. In this paper we will assume that this will not happen.

An important difference between the Swedish and US system is that, there is no real appreciation of benefits after retirement in the US.
} 


$$
\begin{gathered}
D B P O_{i \tau}=0.1 \min \left[L_{i 64}^{P} ; 320\right]+ \\
0.65 \min \left[\max \left(L_{i 64}^{P}-320 ; 0\right) ; 850-320\right]+ \\
0.325 \min \left[\max \left(L_{i 64}^{P}-850 ; 0\right) ; 1270-850\right] .
\end{gathered}
$$

All payouts from the $N D C$ pension plan are forfeited in the event of death and for simplicity, we assume the same for the defined benefit plan.

\subsection{Taxes}

Wage and retirement income $L_{i \tau}$ can be defined as

$$
L_{i \tau}=\left\{\begin{array}{cc}
e^{l_{i \tau}} & , \tau<65 \\
P O_{\tau}\left(R_{\tau-1}^{l} \cdot N D C_{i \tau-1}\right)+D B P O_{i \tau} & , \tau \geq 65 .
\end{array}\right.
$$

According to the present ${ }^{11}$ Swedish tax rules, labour income and pension benefits at the same rates, but separately from capital income. To calculate net income $L_{i \tau}^{n}$, we first deduct a general allowance of 10 , then a municipal tax of $30 \%$, a government tax of $20 \%$ on all income above 300 and finally an additional government tax of $5 \%$ on incomes above 450 . Net income is bounded below by the social welfare minimum benefit at 60 , which also applies to retireés in the form of a government guaranteed pension.

$$
\begin{aligned}
L_{i \tau}^{n}= & \max \left[L_{i \tau}-0.3 \max \left(L_{i \tau}-10 ; 0\right)-\right. \\
& \left.0.2 \max \left(L_{i \tau}-300 ; 0\right)-0.05 \max \left(L_{i \tau}-450 ; 0\right) ; 60\right] .
\end{aligned}
$$

All the threshold values that create kinks in tax rates and benefits ${ }^{12}$ are appreciated by the expected national labour income growth $\mu^{l}$, except the social welfare minimum benefit, which is constant in real terms.

\footnotetext{
${ }^{11}$ We use the tax rules for incomes earned 2003 .

${ }^{12}$ This is the same as in the US since the "bend points" when calculating the primary insurance amount (PIA) are adjusted by average earnings growth.
} 


\subsection{Assets}

There exist one risky and one risk-free asset with after tax real simple returns equal to $R_{\tau}^{s}$ and $R^{f}$ respectively. Excess return is defined as

$$
R_{\tau}^{s}-R^{f}=\mu^{s}+\eta_{\tau}
$$

and correlated with the group aggregate innovation in permanent labour income $\xi_{k}$, which allow for a group specific sensitivity to the risky asset,

$$
\left[\begin{array}{l}
\boldsymbol{\xi} \\
\eta
\end{array}\right] \sim N\left(\left[\begin{array}{l}
\mathbf{0} \\
0
\end{array}\right],\left[\begin{array}{cc}
\boldsymbol{\Sigma} & \boldsymbol{\sigma}_{\xi \eta} \\
\boldsymbol{\sigma}_{\xi \eta}^{\prime} & \sigma_{\eta}^{2}
\end{array}\right]\right)
$$

\subsection{Private savings and consumption}

Each individual starts her "optimization life" with initial wealth set to $\digamma$. In pre-retirement years, the individual receives a wage and in subsequent years, the individual will receive retirement benefits. The individual has two control variables - the proportion of cash on hand to consume $\theta_{\tau}$ and what proportion of savings $\alpha_{\tau}$ to allocate to the risky asset. The cash on hand or disposable wealth is therefore,

$$
X_{i \tau}=\left\{\begin{array}{cl}
{\left[R^{f}+\alpha_{i \tau-1}\left(\mu^{s}+\eta_{\tau-1}\right)\right]\left(1-\theta_{i \tau-1}\right) X_{i \tau-1}+L_{i \tau}^{n}} & , \tau>\tau_{0} \\
\digamma_{i}+L_{i \tau}^{n} & , \tau=\tau_{0}
\end{array}\right.
$$

and

$$
C_{i \tau}=\theta_{i \tau} X_{i \tau}
$$

Finally, we impose both borrowing and short sales constraints, i.e.,

$$
\begin{aligned}
& 0 \leq \theta_{i \tau} \leq 1 \\
& 0 \leq \alpha_{i \tau} \leq 1
\end{aligned}
$$




\subsection{Optimization}

The problem can be characterised as having four state variables $\tau, v, X$ and $N D C$ and two choice variables $\theta$ and $\alpha$ as well as the stochastic variables $\epsilon, u, \xi^{A}$ and $\eta$. The value function of the investor's intertemporal consumption and investment problem can be written as

$$
\begin{gathered}
V_{\tau}\left(\Gamma_{\tau}\right)=\max _{\theta_{\tau}, \alpha_{\tau}}\left\{\frac{C_{\tau}^{1-\gamma}}{1-\gamma}+\delta E_{\tau}\left[p_{\tau} V_{\tau+1}\left(\Gamma_{\tau+1}\right)+\left(1-p_{\tau}\right) b \frac{D_{\tau+1}^{1-\gamma}}{1-\gamma}\right]\right\} \\
\Gamma_{\tau}=\left\{X_{\tau}, v_{\tau}, N D C_{\tau}\right\}
\end{gathered}
$$

The solution to this maximisation problem gives us the state dependent policy rules,

$$
\begin{gathered}
\theta_{\tau}=\theta_{k \tau}\left(\Gamma_{\tau}\right), \\
\alpha_{\tau}=\alpha_{k \tau}\left(\Gamma_{\tau}\right) .
\end{gathered}
$$

Since there is no analytical solution to this constrained optimization problem, we solve the problem numerically using standard methods (cf. Judd (1998)). The problem is solved by backward recursion from the final year - 100. A description of the procedure is found in Appendix A.

\section{CALIBRATION OF PARAMETERS}

\subsection{Estimation of labour income process}

This section describes the estimation of the labour income process. Appendix B gives a more detailed description of the methodology used.

We estimate the parameters in the labour income process by using LINDA data for the years 1992 to 2002. LINDA covers 3.35 percent of the Swedish population (more then 300000 individuals plus their family members) and is described in Edin and Fredriksson (2000). The definition of income includes, in addition to wages, all taxable social benefits, primarily compensation for unemployment, sickness and early retirement. Data was divided into six non-intersecting groups, defined by educational status $^{13}$ and sex. The predictable component of labour income was estimated separately for each

\footnotetext{
${ }^{13}$ The three educational groups are: individuals without gymnasium (high school) degree, individuals with gymnasium
} 
group and the regressors include dummy variables for marital status and age as well as the number of children in four separate age intervals. Parameter estimates are presented in Table C.3.

We then estimate a polynomial of degree three on the age dummies and the averages of the characteristics to obtain the deterministic component of labour income $\exp \left\{f_{k}\left(\tau, \overline{\mathbf{Z}}_{k \tau}\right)\right\}$, cf. Table C.2. Two findings are notable. First, individuals with an University degree experiences significantly faster income growth in mid-life. ${ }^{14}$ This result match the stylised facts from the US, (cf. Cocco et al. (2005), Gourinchas and Parker (2002) and Hubbard et al. (1995)). Secondly, within each educational group, men have higher incomes in all stages of the life-cycle when compared to their female counterparts.

The variances of the permanent and transitory components, $\sigma_{u}^{2}$ and $\sigma_{\varepsilon}^{2}$, of shocks to labour income as specified in Equation (2) were estimated using the methodology of Carroll and Samwick (1997). The results are presented in Table C.5 along with the results by Carroll and Samwick (1997), who based their study on household gross income and Cocco et al. (2005), who estimated on household net income.

Our results show a strikingly lower variation in the transitory component when compared to both of these studies. This was surprising, since we expected a diversification effect within the family and that the lower variation in net $v s$ gross income, would reduce the residual variation.

One possible explanation could be that measurement errors are treated in the same way as transitory income shocks and thereby increasing the estimated variance. Comparing register based and survey data, Duncan and Hill (1985) and Bound et al. (1994) demonstrates that survey data, such as the PSID, can give rise to measurement errors, which may have a large effect on estimated variances.

Our lower estimates can therefore partially be explained by, that data in LINDA is based on filed tax reports which are more precise. Gourinchas and Parker (2002), p 81, states that: "a reasonable guess might be that roughly a third of the variance of measured income growth is due to mismeasurement and that most of this is transitory".

degree but no University degree, and finally individuals with an University degree.

${ }^{14}$ This is probably partly due to a selection bias, since we would expect those with university aptitude to perform better even without a degree, $c f$. Hausmann and Taylor (1981). 


\subsection{Individual parameters}

We use a standard set of assumptions with respect to the individual parameters for the reference case. First, we set the coefficient of relative risk aversion $\gamma$ to 5 and the discount factor $\delta$ to 0.98 . The survival probabilities $p$ are sex dependent and taken from the Swedish lifeinsurers (cf. Figure C.2) when underwriting new policies, i.e. it is forward looking ${ }^{15}$. The bequest parameter $b$ is set to 1 . The importance of the risk aversion parameter $\gamma$ will be elaborated on when we do the sensitivity analysis in Section 3.4.

\subsection{Assets and correlations}

In the optimization, we set the risk-free after tax rate $R^{f}-1$ equal to $1.5 \%$, which is lower than the $2 \%$ in Cocco et al. (2005), but fits with the present gross return of less than $2 \%$ for long dated index linked bonds. The mean after tax equity premium $\mu^{s}$ is set to $3 \%$, which is low when compared with historical average, but corresponds well with forward-looking estimates ( $c f$. Claus and Thomas (2001), Fama and French (2002) among others). Volatility $\sigma_{\eta}$ was set to $20 \%$ for the risky asset.

Next, we follow the procedure of Cocco et al. (2005) to estimate the correlation $\varrho_{\xi_{k} \eta}$ between group specific permanent labour income shocks $\xi_{k \tau}$ and lagged equity returns $\eta_{\tau-1}$. In Table C.1, we present the estimated correlation using the returns of the Swedish equity index OMX and the 12 month Swedish Treasury Bill as proxies for equity returns and the risk-free rates, respectively. Due to the uncertainty in the equity premium, we analyse the sensitivity in Section 3.4 of our results with respect to an increase in this parameter.

It can be noted that university educated women and men defines the range for the correlation, with women having the lowest. One possible explanation could be that women with an university degree to a higher degree are publicly employed. We also set the growth in average labour income $\mu^{l}$ to $1.8 \%$, which is the estimate used by the National Social Insurance Board. Finally, the initial wealth $\digamma$ is set to 47 , corresponding to the mean wealth for individuals in the age between 20 and 23 .

\footnotetext{
${ }^{15}$ The difference from todays realised mortality, is that both sexes are expected to live longer and that the difference between men and women increase.
} 


\section{RESULTS}

To study the behaviour of the individual belonging to a specific group, we now use the policy functions in Equations (18) (consumption share) and (19) (risky share) that describe the optimal state dependent behaviour. The contour plots in Figures C.12 and C.13 show the policy functions for risky weight and consumption share respectively, with the state variables age and $N D C$ held constant. At retirement, the permanent component of labour income shock $\nu$ decides the defined benefit for the remainder of the life. For large values of cash on hand, the optimal policy in risky weight coincides with the complete market solution ${ }^{16}$. When the ratio of cash on hand to the implicit pension assets $\left(\frac{X}{N D C+D B}\right)$ decrease, both the consumption and risky share will increase. As the ratio decrease even further, the dominating savings motive is bequest and therefore the risky share is reduced back to the complete market solution. The curvature in policy functions are caused by the defined benefit payout being more sensitive to changes in permanent income ( $c f$. Equation (8)). Since defined benefit resembles a risk-free asset, the agent will compensate by increasing both the risky and consumption share.

[Insert fig C.12 and C.13 here]

To study the potential outcomes of the model, we simulate the behaviour of an individual (one from each group), by generating 30000 random trajectories through time. These simulated distributions cannot be directely compared with the actual distributions of today, since the latter are conditional on one realisation for several individuals. In addition, the present population lived under very different conditions in terms of productivity level, pension systems, etc. compared to the present and future that we model.

The top and bottom pictures in Figure C.14 show the simulated individual frequency distribution across age for the risky weight and consumption share, respectively. We note that the short sale constraint is effective for most trajectories in mid-life. Outside of this period, there is a wide range of optimal choices dependent on other state variables beside age.

[Insert fig C.14here]

\footnotetext{
${ }^{16}$ Where risky share is $\alpha=\frac{\mu^{s}}{\gamma \sigma_{\eta}^{2}}$.
} 


\subsection{Reference case}

In this section, we present the cross-section averages from the simulation. In Figures C.3 and C.4 we plot the average of cash on hand, consumption, consumption share, retirement wealth in the $N D C$ account, after tax income and the portfolio allocation for an individual from each group.

We note that the individual tries to smooth consumption over life, which can be seen if we compare the wage and consumption profiles. However, an increasing and uncertain labour income together with the borrowing constraint, creates a humped shaped consumption profile, as in eg. Gourinchas and Parker (2002). The decline in consumption during retirement is primarily due to mortality risk, which gives rise to a more flat consumption profile for women then for men. It should also be noted that consumption increases with after tax income and peaks close to retirement.

The peak in wages occurs later than in empirical cross-section data since the wage profile is forward looking, i.e. it includes the expected increase in wages from the average productivity growth.

The cap on the contribution amount has the effect that there are only small differences in $N D C$ wealth at retirement ( $c f$. Figure C.3), even though wages differ markedly between groups. However, the company sponsored defined benefit plan compensates high income earners for the cap, making the retention rates almost equal across the groups ( $c f$. Table C.4). This result corresponds well with projections from dynamic micro-simulations ( $c f$. Flood (2003)).

In order to alleviate the drop in income at retirement, the individual also saves voluntarily to even out consumption over the life-cycle. As can be seen in the average for the consumption share, retirement saving does not start before mid-life. Prior to this, savings are driven by precautionary and bequest motives. Consequentially, the cash on hand during early life is largely invested in the risk-free asset. When private savings for retirement increases during mid-life, wealth is allocated to the risky asset, since the implicit assets in mandatory pension schemes and future wages are closer substitutes to the risk-free asset.

[Insert fig C.3 and C.4 here]

As cash on hand becomes relatively larger in comparison to the implicit assets, the investor compensates by reducing the risky weight. Although the implicit assets are less risky, they are not risk-free. 
The risk is most pronounced for university-educated men. This group have both a larger relative exposure to the defined benefit asset and a higher correlation between their wages and the stock market. They will therefore, choose a lower risky allocation from mid-life until retirement, when the defined benefit asset becomes risk-free.

[Insert fig C.1 here]

The profile for cash on hand has the charateristic life-cycle shape that we find in data ${ }^{17}(c f$. Figure C.1). We also see the effect of the gender difference in longevity on consumption and savings behaviour. During retirement women will decrease their cash on hand at a lower rate than men will, since they expect to distribute their savings for consumption over a longer period.

\subsection{Valuing the $N D C$ account}

Forced saving in early life, when the wage profile is increasing, raises the question of the value of the $N D C$ asset. In Equation (20), we express the value of the $N D C$ asset $^{18}$ in terms of cash on hand $X$, by calculating the expected value of the ratio of the respective derivatives of Equation (17),

$$
E_{\tau_{0}}\left[\frac{\partial V_{\tau}\left(\Gamma_{\tau}\right)}{\partial N D C} / \frac{\partial V_{\tau}\left(\Gamma_{\tau}\right)}{\partial X}\right]
$$

[Insert fig C.5 here]

We note in Figure C.5 that, the marginal value that an individual attributes to the $N D C$ account is low in early life. This result is primarily caused by forced retirement saving at a time in life when consumption is preferred. Moreover, since $N D C$ wealth cannot serve the precautionary motive, the agent will make additional savings as a precaution. As the wealth in the $N D C$ account becomes larger in comparison to private wealth ( $c f$. Figure C.6), the marginal value of $N D C$ asset will decrease even further, since the $N D C$ asset primarily fulfils a small bequest motive. The increase in marginal value

\footnotetext{
${ }^{17}$ The two profiles are not directely comparable since the simulated profile relates to future wealth whereas the actual data is a cross-section from year 2002. In our simulations, there is a peak at age 65 since we assume a fixed retirement date. In reality, there is a lot of variation in retirement age, making the peak less pronounced. After the age of 80 the number of survivors decrease our sample rapidly and expected wealth is potentially biased upwards, due to survival probabilities being correlated with wealth, cf. Modigliani and Jappelli (1998).

${ }^{18}$ For comparative purposes, since bequest can only come from cash on hand $X$, we change the model in two ways. First, we allocate the wealth in the $N D C$ account to bequest in case of death, but taxed with the median tax rate of $30 \%$. Second, we remove the inheritance gains in the $N D C$ system.
} 
up until age 40 stems from that the retirement savings motive becomes stronger. ${ }^{19}$

The $N D C$ asset have similar characteristics as a combination ${ }^{20}$ of the risk-free and risky asset, the relative value converges to the median after tax value of $70 \%,(c f$. Equation (10)). As pension benefits are generally lower than wages, only a few trajectories will be in the higher tax brackets during retirement, which is why only the highest income group will experience a slightly smaller value due to higher taxation.

[Insert fig C.6 here]

\subsection{Risk in the $N D C$ account}

This model has five "assets"; risk-free, risky, defined benefit, future wages and the $N D C$ asset, of which the last three are non-tradeable. In this section, we analyse the diversification properties of the $N D C$ asset. As described in Section 2, the $N D C$ return has a volatility of about $2 \%$ and is correlated with both group permanent income shocks and the return of the risky asset. Albeit, that the volatility is rather low, the risk in the $N D C$ asset has a major impact on individual utility since this is on average the largest asset at retirement.

The economic importance of the risk in the $N D C$ system can be analysed by computing the utility gains associated with two alternative regimes. The first regime makes the $N D C$ return riskfree, while the second regime makes the return independent of both group permanent income shocks and the return of the risky asset. In both cases, the expected simple return ${ }^{21}$ of the $N D C$ account is held constant and equal to that of the reference case.

The utility gains are presented as consumption and bequest equivalent units $C B E$. A one percent change in $C B E$ represents the same percentage change in consumption and bequest in all possible states for the remainder of life. Equation (17) is solved with the new covariance matrix and the corresponding policy responses, $\theta_{k \tau}\left(\Gamma_{\tau}\right)$ and $\alpha_{k \tau}\left(\Gamma_{\tau}\right)$ are derived. We then compute the value function $V_{\tau}^{a}\left(\bar{\Gamma}_{\tau}^{r}\right)$ for each age, where $\bar{\Gamma}_{\tau}^{r}$ is set equal to the average of each state variable from the reference

\footnotetext{
${ }^{19}$ The ratio has a peak at the age of 50 for University educated men, as their income is often taxed at a higher rate, whereas the bequest of $N D C$ wealth is only taxed at $30 \%$. As the probability of bequest prior to retirement decrease with age the ratio falls.

${ }^{20}$ The same Sharpe ratio, the $N D C$ asset is approximately equal to a $10 \%$ investment into the risky and the remainder into the risk free asset.

${ }^{21} \mu_{l}$ is increased by $\frac{1}{2} \sigma_{\xi}^{2}$ in the risk-free regime.
} 
case. Superindices $a$ and $r$ refer to the alternative and reference case, respectively. The gain in $C B E$ is then defined as

$$
G_{\tau}=\left[\frac{V_{\tau}^{r}\left(\bar{\Gamma}_{\tau}^{r}\right)}{V_{\tau}^{a}\left(\bar{\Gamma}_{\tau}^{r}\right)}\right]^{\frac{1}{1-\gamma}}-1 .
$$

In Figure C.7, we have plotted $G_{\tau}$ from making the $N D C$ account independent or risk-free. The groups shown are men with an University degree and women with Compulsory school only, which are our extreme groups with respect to earnings. Our two extreme groups depict a similar pattern.

[Insert fig C.7 here]

In the previous section, we showed that the value that a young individual attributes to the $N D C$ account is very small, since consumption is prefered and savings are primarily driven by precautionary motives. The risk characteristics will therefore be of little importance for a young individual when determining expected lifetime utility.

As the expected ratio of marginal utilities increases ( $c f$. Figure C.5), the sensitivity to changes in risk characteristics also increases. When the retirement date comes closer, the part of the implicit assets that originate from future wages decreases, making $G_{\tau}$ decline. At retirement, the defined benefit asset will become risk-free, resulting in a more pronounced drop in $G_{\tau}$ for the high-income group. After retirement, the $G_{\tau}$ continue to decrease, as the ratio of private to $N D C$ wealth increase,

\section{cf. Figure C.6.}

At the peak, the gain in consumption and bequest equivalent units from having a risk-free $N D C$ asset is considerable and ranges between $1.6 \%$ to $1.8 \%$.

Interestingly, about two-thirds of the gains originates from the elimination of the dependency between $N D C$ asset returns and both group permanent income shocks and risky asset returns. During working life, the $N D C$ asset return is correlated with future wages and defined benefits, as well as with risky asset returns. When in retirement, only the latter correlation remains, but the proportional gain $\left(\frac{2}{3}\right)$ still holds regardless of age $\mathrm{e}^{22}$. The existence of a risky asset, correlated with $N D C$ wealth,

\footnotetext{
${ }^{22}$ Therefore, to the extent that $N D C$ schemes are supported by buffer funds (as in Sweden) to even out differences between contributions and benefits, such funds should actively manage its assets with the aim to minimise the correlation with wages. Idiosyncratic risks in such schemes, eg. demographic risks, are of less relevance. This is in stark contrast to how some of these funds interpret their risks. When describing their optimization problem, one fund stated that: "The optimization of risk-return was done relative to the minimum risk portfolio... This was considered to be the portfolio showing the smallest tracking error relative to the income index" Wassum (2002).
} 
underlines the risk aspects in $N D C$ during retirement. This would have been overlooked if private wealth only could be invested in a risk-free asset.

\subsection{Robustness and sensitivity}

It is important to note that our parameterisation is conservative, with respect to the effects on the valuation of the $N D C$ account analysed in Section 3.2: including the $F D C$ contribution of $2.5 \%$ would increase the forced saving; the $N D C$ return is high and the equity premium is low, making these assets approximately equal with respect to Sharpe ratios; and finally the impatience parameter is high which alleviates the negative consequences of forced saving. In order to test to what extent our results are influenced by the parameterisation, we perform two sensitivity tests ${ }^{23}$. First, we decrease the coefficient of relative risk aversion $-\gamma$ from 5 to 2 . This parameter has the property that it controls both the elasticity of intertemporal substitution and the risk aversion. Our results, especially in Section 3.2, are driven by the unevenly distributed consumption across age and are therefore likely to be affected by a change in the elasticity of intertemporal substitution. Furthermore, $\gamma$ determines the risk aversion and hence the analysis of the risk in the NDC account in Section 3.3.

Secondly, we increase the risk premium to $4 \%$, since our reference case with $3 \%$ is low both in comparison with the empirical average and to other studies (eg. Cocco (2005), Cocco et al. (2005), Gomes and Michaelides (2005) and Yao and Zhang (2005)) in which $4 \%$ were assumed.

[Insert fig C.8 here]

Changing the coefficient of relative risk aversion $\gamma$ from 5 to 2 has a dual effect on the value attributed to the $N D C$ asset. On the one hand, the increase in elasticity of intertemporal substitution raises the value of the $N D C$ asset when the individuals are young and liquidity constrained, since it makes agents more willing to substitute consumption over time. On the other hand, a lower $\gamma$ induces a higher demand for risky assets and the agent will become constrained by the short sales constraint on the risk-free asset. The $N D C$ asset is a closer substitute for the risk-free asset than for the risky asset and hence an undesirable investment for an agent with relatively low risk aversion.

\footnotetext{
${ }^{23}$ We only present the results for the group Men with a High School Degree, since this group is the most numerous and their wage profile is closest to the average over all groups.
} 
[Insert fig C.9 here]

Early in life, the two effects offset each other, making the value attributed to the $N D C$ account approximately equal to that in the reference case ( $c f$. Figure C.9). Later in life, as consumption reaches the lifetime average, the effect of a higher elasticity of intertemporal substitution diminishes, resulting in a substantially lower value attributed to the $N D C$ asset than in the reference case. During the last ten years of life, the importance of the non-negativity constraint on the risk-free asset is decreasing, making the marginal value of the $N D C$ asset equal to the after tax value.

Changing the risk premium, depreciates the relative value of the $N D C$ asset to cash on hand. This effect is most pronounced for a young individual, who is forced to hold this asset for a longer period.

[Insert fig C.10 here]

In Figures C.10 and C.11, we demonstrate the sensitivity of our results in Section 3.3, with respect to the same changes in risk premium and risk aversion. Lowering the individual risk aversion, will reduce the gains from making the $N D C$ asset return independent (Figure C.11) or risk-free (Figure C.10). A higher risk premium relative to the reference case will increase the gains, because the individual will now have a larger proportion of cash on hand in the risky asset. However, the proportion of gains $\left(\frac{2}{3}\right)$ that stems from independency relative to zero risk will be approximately intact.

[Insert fig C.11 here]

\section{CONCLUSION AND COMMENTS}

This paper contributes to the understanding of the risk characteristics and welfare effects of $N D C$ pension systems.

We present a life-cycle model of a borrowing constrained individual's consumption and portfolio choice in the presence of uncertain labour income and realistically calibrated tax and pension systems. The pension scheme consists of both a defined benefit and a notionally defined contribution part, the latter being indexed to stochastic aggregate labour income growth.

We investigate the utility effects due to forced retirement saving into an asset with returns that are determined by labour income growth. First, our findings show that individuals attribute little 
value to their pension savings in early life. We expect this result to hold qualitatively for any pension scheme with a flat contribution rate across age and is therefore independent of the country specific calibration. Welfare gains can therefore be achieved by postponing the contribution from early to mid working life, while keeping the duration of the $N D C$ account unchanged. Such a change could also lead to an increase in supply and demand for young labour and thereby encourage an earlier entry into the labour market.

Secondly, we find that it is the dependency between labour income growth and $N D C$ returns rather than the volatility in $N D C$ returns, which is the most important source of welfare loss. The reason being that it makes the returns of the $N D C$ asset correlated with individual future wages and defined benefits, as well as with risky asset returns. This effect is essential when analysing the consequences of the proposed change (cf. CSSS (2001)) in US Social Security Benefit indexation that will make retention rates negatively correlated with aggregate wages ( $c f$. Munnell and Soto (2005)). The positive welfare effects of this negative correlation will therefore partly compensate for the lower expected retention rate.

Another implication, is that to the extent that $N D C$ schemes are supported by buffer funds (as in Sweden) to even out differences between contributions and benefits, such funds should actively manage its assets with the aim to minimise the correlation with wages. Idiosyncratic risks in such schemes, eg. demographic risks, are of less relevance. Societal gains could therefore be achieved by reducing dependency between the $N D C$ asset and aggregate income. This topic have been discussed earlier in eg. Shiller (2003).

The introduction of a risky asset into a model with these risk characteristics, demonstrates the limited inter-generational risk sharing that can be achieved through a NDC asset dependent on average wage growth.

\section{APPENDIX A: OPTIMIZATION}

Since there exist no analytical solution to the Equation (17), we solved it numerically by backward 
recursion. The continuous state variables (cash on hand $X$, retirement savings account $N D C$ and permanent component of shocks to labour income $v$ ) and choice variables (consumption weight $\theta$ and risky weight $\alpha$ ) were discretised. The grid of points in $X$ and $N D C$ was distributed exponentially, whereas an uniformly spaced grid were used for $v, \theta$ and $\alpha$. The introduction of tax and pension systems that are not proportional to wages prohibits us from normalising the problem, i.e. we cannot reduce the dimension of the state space, as has been done in eg. CCGM and Gomes and Michaelides (2005).

Due to zero survival probability in the final year, the value function is simplified since cash on hand is partly consumed and the remainder bequeathed. Policies and the value of the Bellman equation were therefore easily determined for each combination of state variables. We approximated the value and policy functions for intermediate points with a third degree polynomial B-spline, eg. de Boor (1978). The value function in the terminal period was then used to compute the value function in the previous period, where the expectation in Equation (17) was evaluated using a Gaussian-Hermite quadrature approximation, eg. Golub and Welsch (1969). Close to any of the kinks in payout or tax functions, we refined the approximation by using a higher number of nodes. For every combination of states, the optimum was found by a grid search in each choice dimension $\theta$ and $\alpha$. This procedure was then iterated backwardly until the initial year.

\section{APPENDIX B: ESTIMATION}

We estimate the parameters in the labour income process by using LINDA data for the years 1992 to 2002. LINDA - a register-based longitudinal data set - consists of a large panel of individuals, which is representative for the population from 1960 and onwards. The data set covers 3.35 percent of the Swedish population (more then 300000 individuals plus their household members) and the data is described in Edin and Fredriksson (2000).

The income data is based on filed tax reports. Our definition of income includes, in addition to wages, all taxable social benefits, primarily compensation for unemployment, sickness and early retirement. We assumed that all individuals with an income less than 100 were voluntarily unemployed 
and they were therefore excluded from the estimation. The data was divided into six non-intersecting groups, defined by educational status and sex. The three educational groups are individuals without gymnasium (high school) degree, individuals with gymnasium degree but no University degree, and finally individuals with an University degree. Individuals with missing values for educational status, approximately 1.2 percent of the sample, were deleted.

The predictable component of labour income was estimated separately for each group using a balanced panel random effects model with an $A R(1)$ disturbance term,

$$
\begin{aligned}
l_{i k t}=\beta_{k 0}+\mathbf{Z}_{i k t} \boldsymbol{\beta}_{k}+\vartheta_{k i}+e_{i k t} & , i=1, \ldots N_{k} \\
e_{i k t}=\rho e_{i k t-1}+\varkappa_{i k t} & , t=1, \ldots, T,
\end{aligned}
$$

where

$$
\vartheta_{i k} \sim N I I D\left(0, \sigma_{\vartheta_{k}}^{2}\right)
$$

and

$$
\varkappa_{i k t} \sim N I I D\left(0, \sigma_{\varkappa_{k}}^{2}\right)
$$

and where $l_{i k t}$ is the logarithm of income adjusted for overall income growth in the economy. $\mathbf{Z}_{i k t}$ includes dummy variables for marital status and age as well as number of children in four separate age intervals. The estimated coefficients are presented in table C.3. After adjusting the age dummies for expected future labour productivity growth, we estimate a polynomial of degree three on the age dummies and the averages of the characteristics to obtain the forward-looking deterministic income profile, $\exp \left\{f_{k}\left(\tau, \overline{\mathbf{Z}}_{k \tau}\right)\right\}$. Table $C .2$ shows the estimated parameters to the income polynomial for each group.

The variances of the permanent and transitory components, $\sigma_{u}^{2}$ and $\sigma_{\varepsilon}^{2}$, of shocks to labour income as specified in Equation (2), were estimated using the methodology of Carroll and Samwick (1997). Define individual residuals from Equation $(22)$, as $l_{i k t}^{*}=l_{i k t}-f_{k}\left(\tau, \mathbf{Z}_{i k \tau}\right)$.The $d$-year variance is 
therefore

$$
E\left(l_{i k t+d}^{*}-l_{i k t}^{*}\right)^{2}=d \sigma_{u_{k}}^{2}+2 \sigma_{\epsilon_{k}}^{2} .
$$

The two parameters in Equation (25), were estimated using OLS on the differences - $d$ and a constant term. We allow for a serial correlation in the transitory term of order $M A(2)$ by only including differences $d>2$. Furthermore, we exclude the maximum difference $d=10$ since there is only one observation. This gives us 35 observations for each individual. The results are presented in Table C.5, along with the results by Carroll and Samwick (1997) and Cocco et al. (2005).

We then follow the procedure of Cocco et al. (2005) to estimate the correlation between labour income shocks and stock returns. Using Equation (2), the first difference in $l_{i k t}^{*}$ can be written as,

$$
\Delta l_{i k t}^{*}=\xi_{k t}+\omega_{i k t}+\Delta \epsilon_{i k t} .
$$

Taking the average over individuals in each group gives us the group aggregate component,

$$
\overline{\triangle l_{k t}^{*}}=\xi_{k t} .
$$

Finally, we estimate the correlations $\varrho_{\xi_{k} \eta}$ by running the following OLS regression,

$$
\overline{\triangle l_{k t}^{*}}=\beta_{k}\left(R_{t-1}^{s}-R_{t-1}^{f}-\mu_{s}\right)+\phi_{t} .
$$

In Table C.1 we present the result from Equation (28), using the return of the Swedish equity index OMX as a proxy for equity returns and the 12 month Swedish Treasury Bill as the risk-free rate. 


\section{REFERENCES}

Attanansio O, J. Banks and S. Tanner, 2002, Asset Holding and Consumption Volatility, Journal of Political Economy 110, 771-92.

Bellman, R. 1961, Adaptive Control Processes: A Guided Tour, Princeton University Press, Princeton, NJ.

de Boor C, 1978, A Practical Guide to Splines, Springer-Verlag, New York, NY.

Bound J, C. Brown, G.J. Duncan and W.L. Rodgers, 1994, Evidence on the Validity of Cross-Sectional and Longitudnal Labor Market Data, Journal of Labor Economics 12, 345-68.

Cocco J.F, 2005, Portfolio Choice in the Presence of Housing, Review of Financial Studies 18, 535-567.

Cocco J.F, F.J. Gomes and P.J. Maenhout, 2005, Consumption and Portfolio Choice over the LifeCycle, Review of Financial Studies 18, 491-533.

Campbell J. Y., J. Cocco, F. Gomes and P. Maenhout, 2001, Investing Retirement Wealth: A life-cycle Model, in John Y. Campbell and Martin Feldstein(eds), Risk Aspects of Social Security Reform, The University of Chicago Press, Chicago, IL.

Carroll C. D., 1997, Buffer-Stock Saving and the Life-Cycle/Permanent Income Hypothesis, Quarterly Journal of Economics 112, 1-55.

Carroll C. and A. Samwick, 1997, The Nature of Precautionary wealth, Journal of Monetary Economics 40, 41-71.

Claus, J. and J. Thomas, 2001, Equity premia as low as three percent? Evidence from analysts' earnings forecats for domestic and international stock markets, Journal of Finance 61, 1629-1666.

Commission to Strengthen Social Security, 2001, Strengthening Social Security and Creating Wealth for all Americans, Report of the President's Commission, www.csss.gov.

Deaton, A. 1991, Saving and liquidity constraints, Econometrica 59, 1221-1248. 
Diamond, P.A., 2002, Social Security Reform ( Lindahl Lectures), Oxford University Press Inc, New York, NY.

Duncan, Greg J. and Daniel H. Hill, 1985, An Investigation of the Extent and Consequences of Measurement Error in Labor-economic Survey Data, Journal of Labor Economics 3, 508-32.

Edin, P. and P. Fredriksson, 2000, Longitudinal INdividual DAta for Sweden, University of Uppsala, working paper 2000:19.

Fama E.F. and K.R. French, 2002, The Equity Premium, Journal of Finance 62, 637-659.

Flavin, M.A. 1981, The Adjustment of Consumption to Changing Expectations about Future Income, Journal of Political Economy 89, 974-1009.

Flood, L.R. 2003, Can we afford the future? An evaluation of the new Swedish pension system, Working paper, School of Business, Economics and Law, Göteborg University.

Friedman M, 1957, A Theory of the Consumption Function, Princeton Univ. Press, Princeton, NJ.

Golub G.H. and J.H. Welsch, 1969, Calculation of Gaussian Quadrature rules, Mathemathics of Computation 221-230

Gomes F. and A. Michaelides, 2005, Optimal Life-Cycle Asset Allocation: Understanding the Empirical Evidence, Journal of Finance 60, No. 2, 869-904

Gourinchas P-O. and J.A. Parker, 2002, Consumption over the life-cycle, Econometrica 70, 47-89

Hall, R.E., and F.S. Mishkin, 1982, The Sensitivity of Consumption to Transitory Income: Estimates from Panel Data on Households, Econometrica 50, 461-81.

Hausmann J.A. and W.E. Taylor, 1981, Panel data and Unobservable Individual effects, Econometrica $49,1377-98$.

Heaton J. and D. Lucas, 2004, Investing Public Pensions in the Stock Market: Implications for Risk Sharing and Asset Prices, working paper, NBER. 
Hubbard, R.G, J. Skinner and S.P. Zeldes, 1995, Precautionary Saving and Social Insurance, Journal of Political Economy 103, 360-99.

Judd K.L.,1998, Numerical Methods in Economics, MIT Press, Cambridge, MA.

Modigliani, F. and R. Brumberg, 1954, Utility Analysis and the Consumption Function: An Interpretation of Cross.section Data, in K. Kurihara, editor, Post Keynesian Economics, Rutgers University Press, New Brunswick, NJ.

Modigliani F. and T. Jappelli, 1998, The age-saving profile and the life-cycle hypothesis, working paper No 9, Centre for Studies in Economics and Finance, Universita Degli Studi de Salerno, Fisciano.

Munnell A.H. and M. Soto, 2005, What Does Price Indexing Mean for Social Security Benefits?, Just the Facts On Retrirement Issues 14, Center for Retirement Research at Boston College.

Riksförsäkringsverket RFV, 2002, The Swedish Pension System Annual Report 2002, www.forsakringskassan.se

Schieber S.J. and J.B. Shoven, 1996, Social Security Reform: Around the World in 80 Ways, American Economic Review 86, 373-77.

Shiller R.J., 2003, The New Financial Order: Risk in the 21s Century, Princeton University Press, Princeton, NJ.

Wassum Investment Partners, 2002, Review of investment strategy setting in the AP-funds - Prepared for the Swedish Ministry of Finance, Stockholm.

Yao R. and H.H. Zhang, 2005, Optimal Consumption and Portfolio Choices with Risky Housing and Borrowing Constraints, Review of Financial Studies 18, 197-238.

Zeldes, S.P. 1989, Optimal Consumption with Stochastic Income: Deviations from Certainty Equivalence, Quarterly Journal of Economics 104, 275-98. 


\section{APPENDIX C: TABLES AND FIGURES}

TABLE C.1

Variance decomposition and estimated return covariances

\begin{tabular}{|c|c|c|c|c|c|}
\hline Group & $\begin{array}{l}\text { Number of } \\
\text { individuals }\end{array}$ & $\begin{array}{c}\text { Estimated } \\
\text { variance of } \\
\text { the permanent } \\
\text { component, } \sigma_{u_{k}}^{2} \\
\end{array}$ & $\begin{array}{c}\text { Estimated } \\
\text { variance of } \\
\text { the transitory } \\
\text { component, } \sigma_{\varepsilon_{k}}^{2} \\
\end{array}$ & $\begin{array}{c}\text { Std. } \\
\text { of the permanent } \\
\text { aggregate } \\
\text { component, } \sigma_{\xi_{k}}\end{array}$ & $\begin{array}{c}\text { Correlations } \\
\text { with Swedish } \\
\text { equity returns, } \\
\varrho_{\xi_{k} \eta} \\
\end{array}$ \\
\hline Full sample & 55532 & & & .01989 & .482 \\
\hline Men & 31540 & & & & \\
\hline $\begin{array}{c}\text { Compulsory } \\
\text { school }\end{array}$ & 6878 & $\begin{array}{r}.00462 \\
(.000137)\end{array}$ & $\begin{array}{r}.00867 \\
(.000379)\end{array}$ & .02008 & .517 \\
\hline $\begin{array}{l}\text { High school } \\
\text { (gymnasium) }\end{array}$ & 14978 & $\begin{array}{r}.00564 \\
(.000112)\end{array}$ & $\begin{array}{r}.00981 \\
(.000313)\end{array}$ & .02020 & .514 \\
\hline $\begin{array}{c}\text { University } \\
\text { degree }\end{array}$ & 9684 & $\begin{array}{r}.00958 \\
(.000226)\end{array}$ & $\begin{array}{r}.01208 \\
(.000625)\end{array}$ & .02187 & .539 \\
\hline Women & 23992 & & & & \\
\hline $\begin{array}{l}\text { Compulsory } \\
\text { school }\end{array}$ & 3485 & $\begin{array}{r}.00403 \\
(.000140)\end{array}$ & $\begin{array}{r}.00623 \\
(.000386)\end{array}$ & .02014 & .477 \\
\hline $\begin{array}{l}\text { High school } \\
\text { (gymnasium) }\end{array}$ & 11119 & $\begin{array}{r}.00460 \\
(.000085)\end{array}$ & $\begin{array}{r}.00741 \\
(.000235)\end{array}$ & .01943 & .444 \\
\hline $\begin{array}{c}\text { University } \\
\text { degree }\end{array}$ & 9388 & $\begin{array}{r}.00634 \\
(.000126)\end{array}$ & $\begin{array}{r}.01000 \\
(.000348)\end{array}$ & .02269 & .290 \\
\hline tandard er & $\mathrm{n}$ parent & & & & \\
\hline
\end{tabular}


TABLE C.2

Coefficients in the age polynomial of the forward-looking income profile

\begin{tabular}{lcccc}
\hline \hline \multicolumn{4}{c}{ Income profile, 2004 KSEK, (AGE-18) } \\
& $\begin{array}{c}\text { Constant } \\
a_{0}\end{array}$ & $\begin{array}{c}\text { Age } \\
a_{1}\end{array}$ & $\begin{array}{c}\text { Age }^{2} \\
a_{2}\end{array}$ & \multicolumn{1}{c}{ Age $^{3}$} \\
\hline Men & & & & \\
Compulsory school & 211.7 & 5.960 & .2514 & -.0048 \\
$\quad$ High school & 221.7 & 4.730 & .4363 & -.00779 \\
$\quad$ University & 190.4 & 4.283 & 1.051 & -.0188 \\
\hline Women & & & & \\
Compulsory school & 189.5 & .758 & .3318 & -.00473 \\
$\quad$ High school & 200.9 & -1.108 & .4566 & -.00645 \\
$\quad$ University & 222.1 & -6.304 & .9188 & -.01277 \\
\hline \hline
\end{tabular}


TABLE C.3

Labour Income Process: Coefficients from Regression

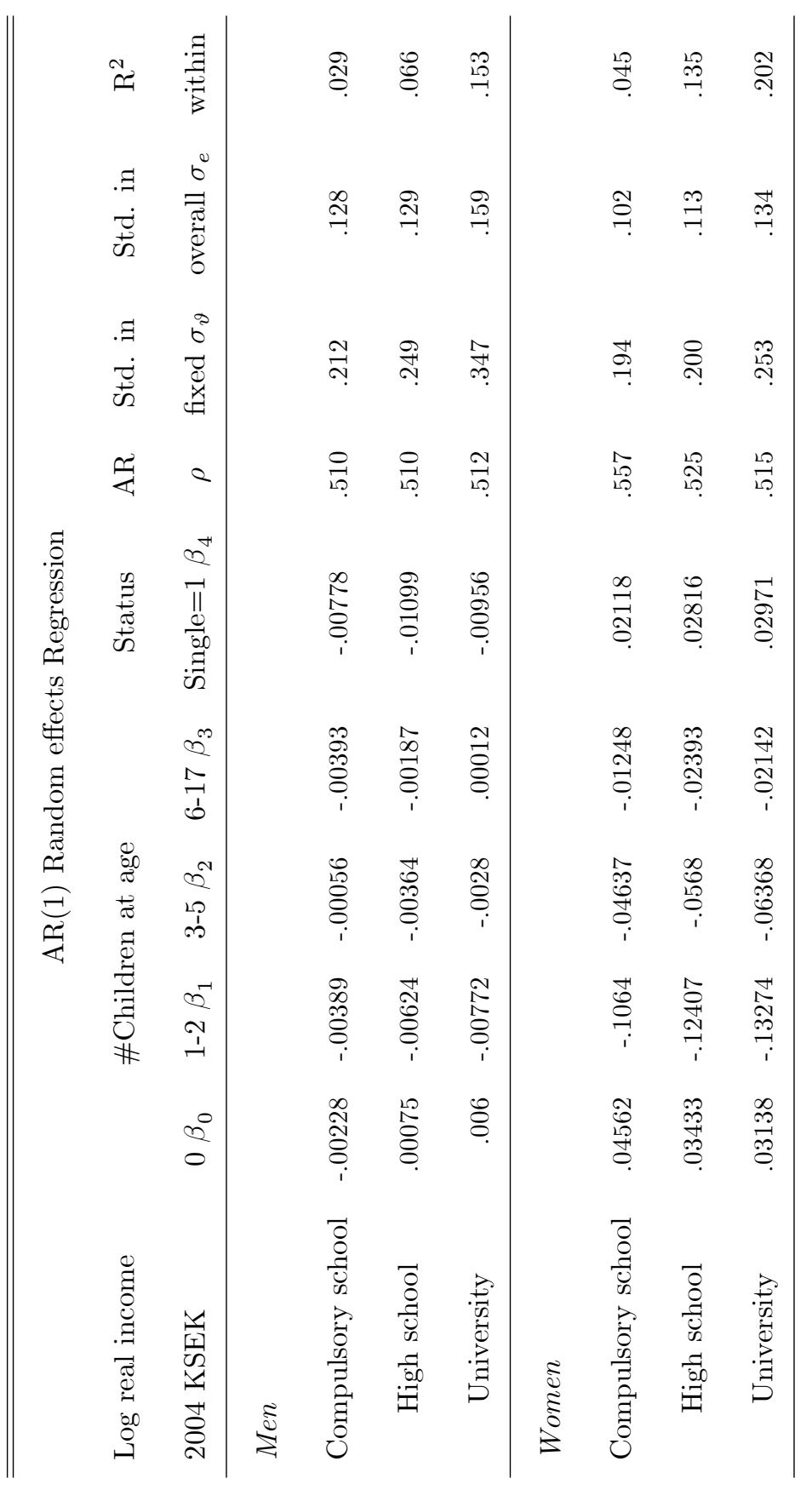


TABLE C.4

Retention rates

\begin{tabular}{|c|c|c|c|}
\hline \multicolumn{4}{|c|}{$\begin{array}{c}\text { Median retention rates as a percentage } \\
\text { of after tax income at retirement in relation to previous year }\end{array}$} \\
\hline \multicolumn{4}{|l|}{ Men } \\
\hline Compulsory school & 57 & 13 & 44 \\
\hline High school & 55 & 13 & 42 \\
\hline University & 58 & 29 & 29 \\
\hline \multicolumn{4}{|l|}{ Women } \\
\hline Compulsory school & 54 & 13 & 41 \\
\hline High school & 55 & 13 & 42 \\
\hline University & 53 & 16 & 37 \\
\hline
\end{tabular}


TABLE C.5

Variance Decomposition

\begin{tabular}{|c|c|c|c|c|}
\hline Description & Men & Women & $C \mathscr{E S}$ & $C G M$ \\
\hline \multicolumn{5}{|c|}{ Variance of transitory shocks $\left(\sigma_{\varepsilon_{k}}^{2}\right)$} \\
\hline Compulsory school & .00867 & .00623 & .0658 & .1056 \\
\hline High school (gymnasium) & .00981 & .00741 & .0431 & .0738 \\
\hline University degree & .01208 & .01000 & .0385 & .0584 \\
\hline \multicolumn{5}{|c|}{ Variance of permanent shocks $\left(\sigma_{u_{k}}^{2}\right)$} \\
\hline Compulsory school & .00462 & .00403 & .0214 & .0105 \\
\hline High school (gymnasium) & .00564 & .00460 & .0277 & .0106 \\
\hline University degree & .00958 & .00634 & .0146 & .0169 \\
\hline \multicolumn{5}{|c|}{ Sensitivity to equity returns $\left(\beta_{k}\right)$} \\
\hline Compulsory school & .0291 & .0279 & & .0956 \\
\hline High school (gymnasium) & .0284 & .0265 & & .0627 \\
\hline University degree & .0347 & .0205 & & .0733 \\
\hline \multicolumn{5}{|c|}{ Correlation with equity returns $\left(\rho_{\xi_{k} \eta}\right)$} \\
\hline Compulsory school & .5167 & .4767 & & .3280 \\
\hline High school (gymnasium) & .5136 & .4436 & & .3709 \\
\hline University degree & .5393 & .2899 & & .5155 \\
\hline
\end{tabular}


Individual Wealth 2002

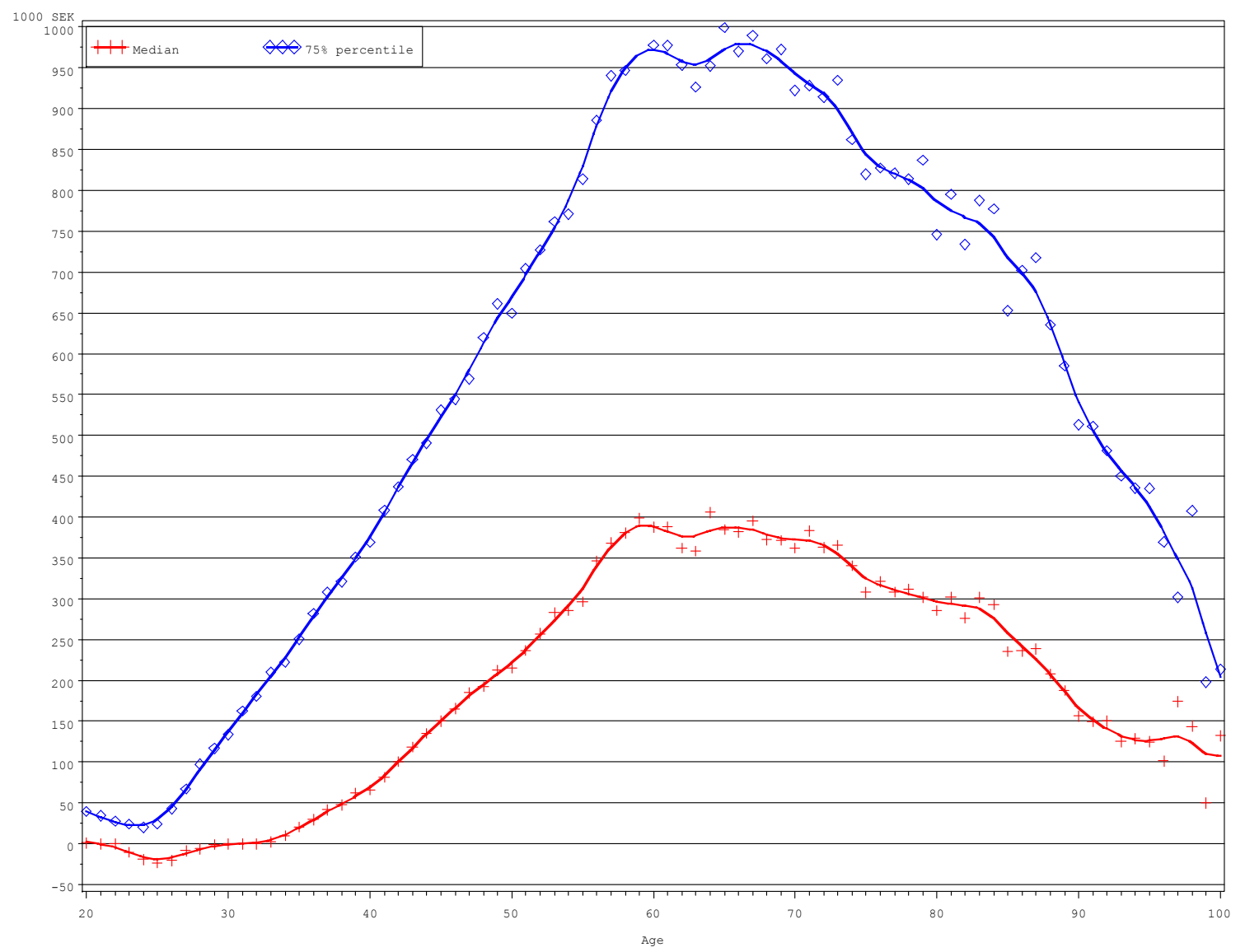

FIG. C.1 Individual net-wealth. Cross-section LINDA data for 2002 based on 499241 individuals. 


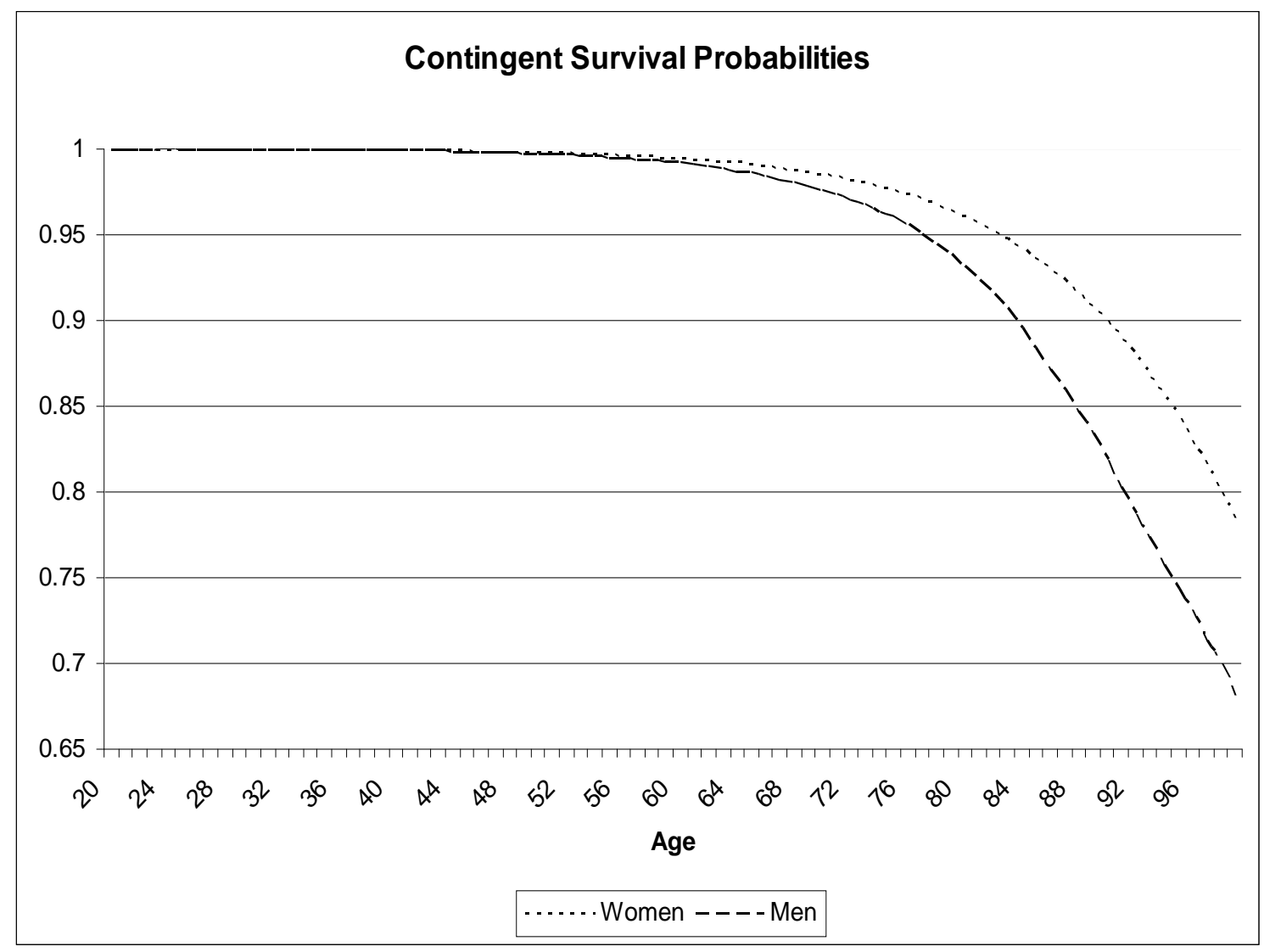

FIG. C.2 Age contingent survival probabilities 

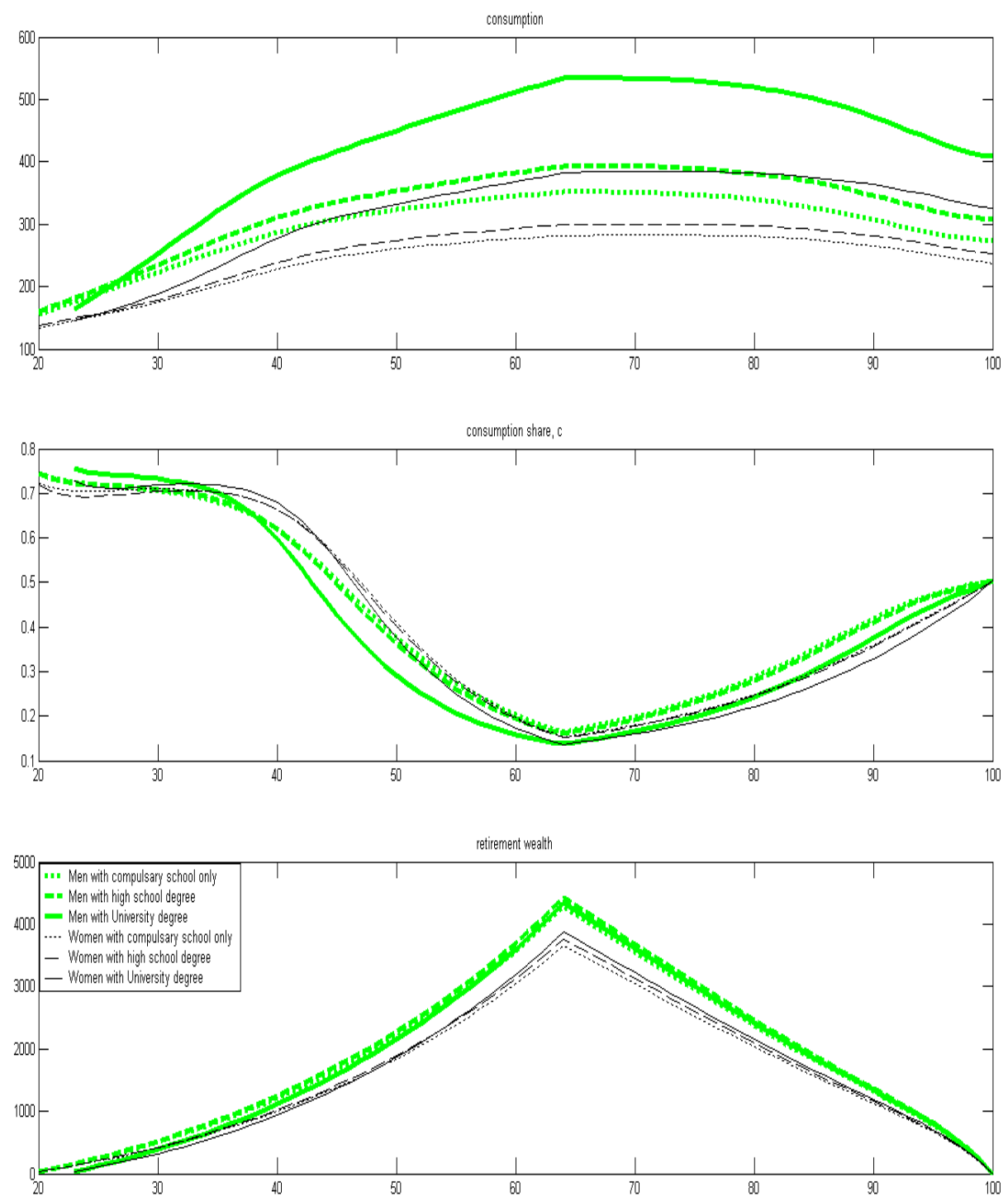

FIG. C.3 Reference case. Age dependent averages from the simulated distributions for each group. 

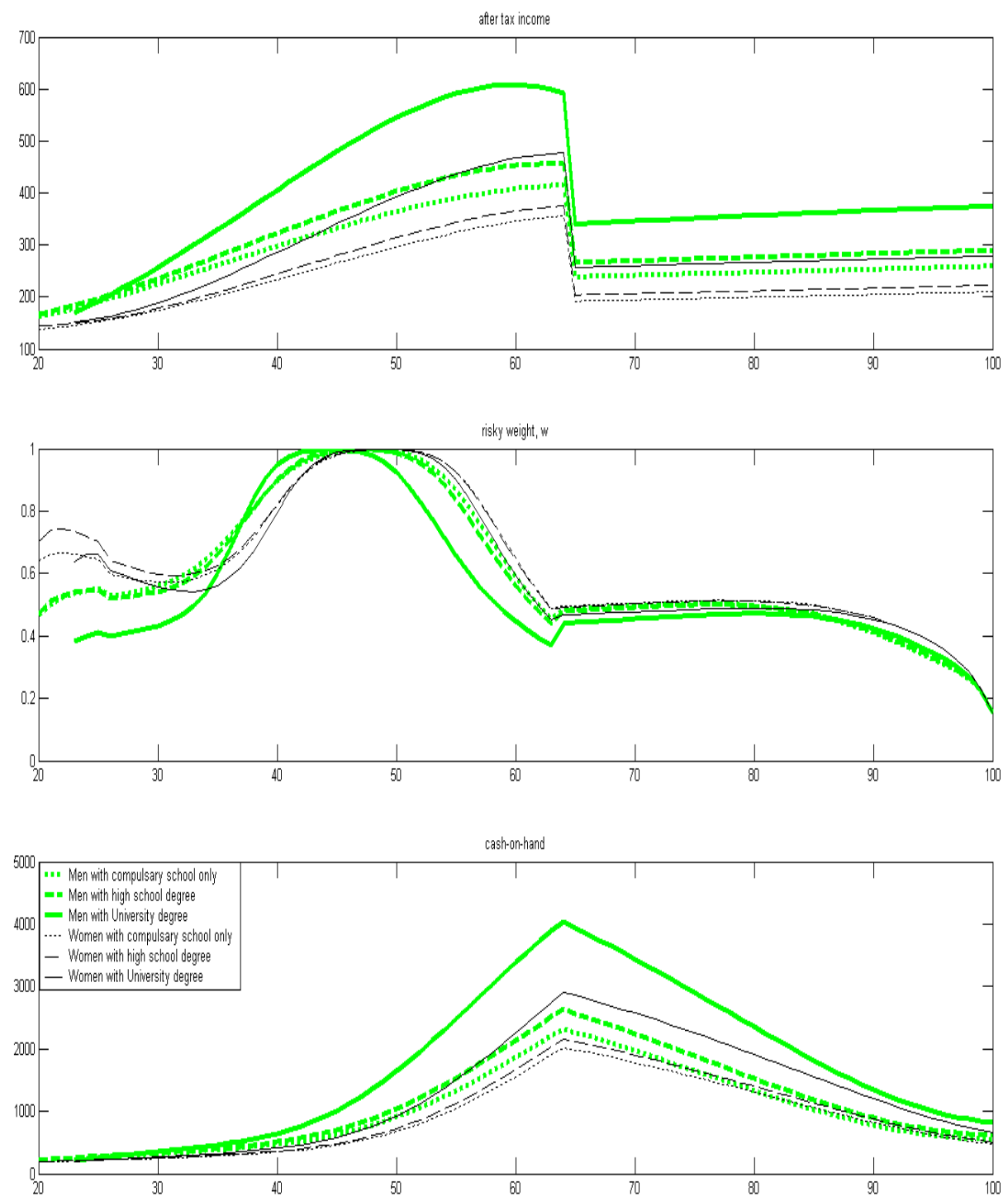

FIG. C.4 Reference case. Age dependent averages from the simulated distributions for each group. 


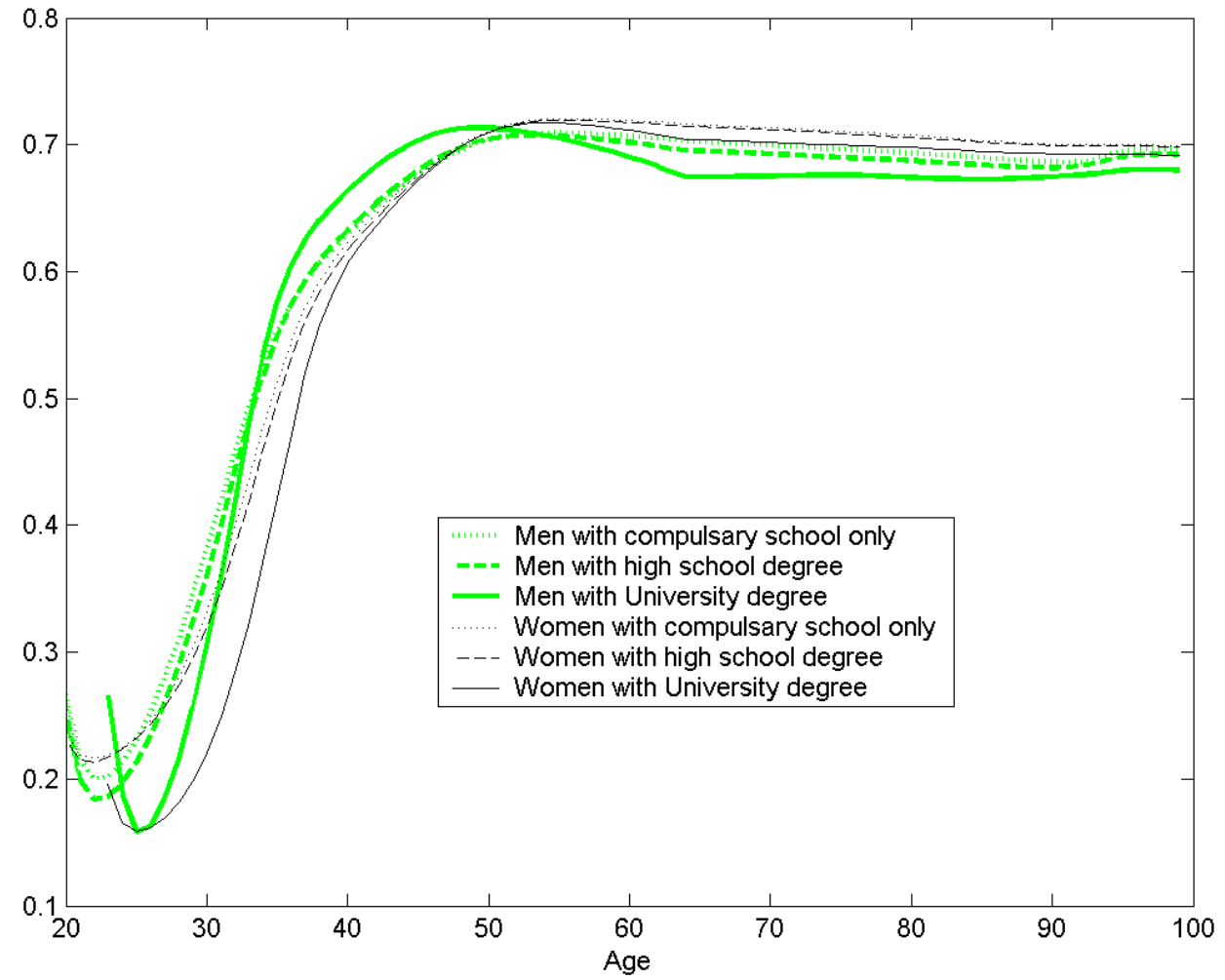

FIG. C.5 Expected Ratio of Marginal Utilities 


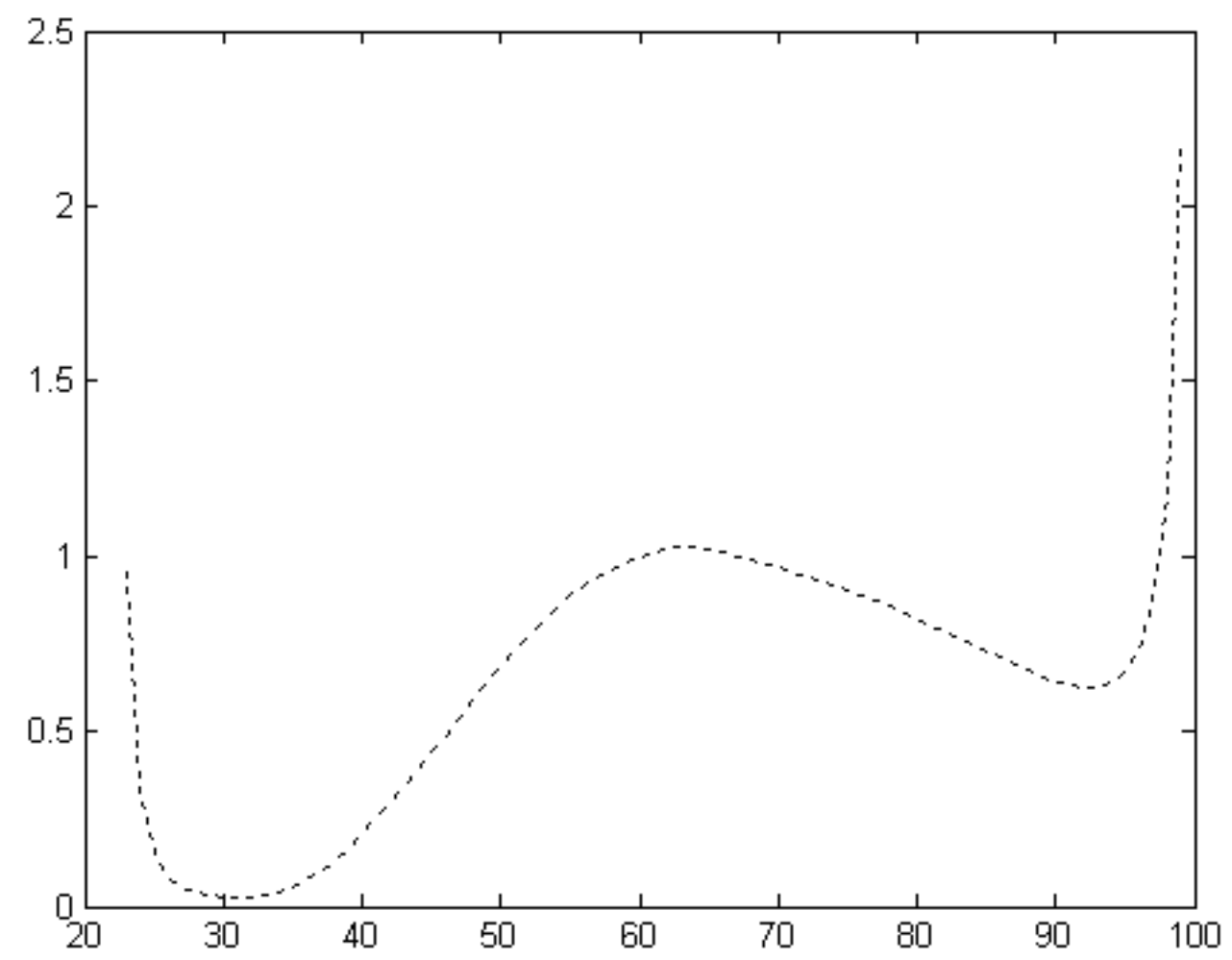

FIG. C.6 Ratio of private to NDC wealth for University educated men 


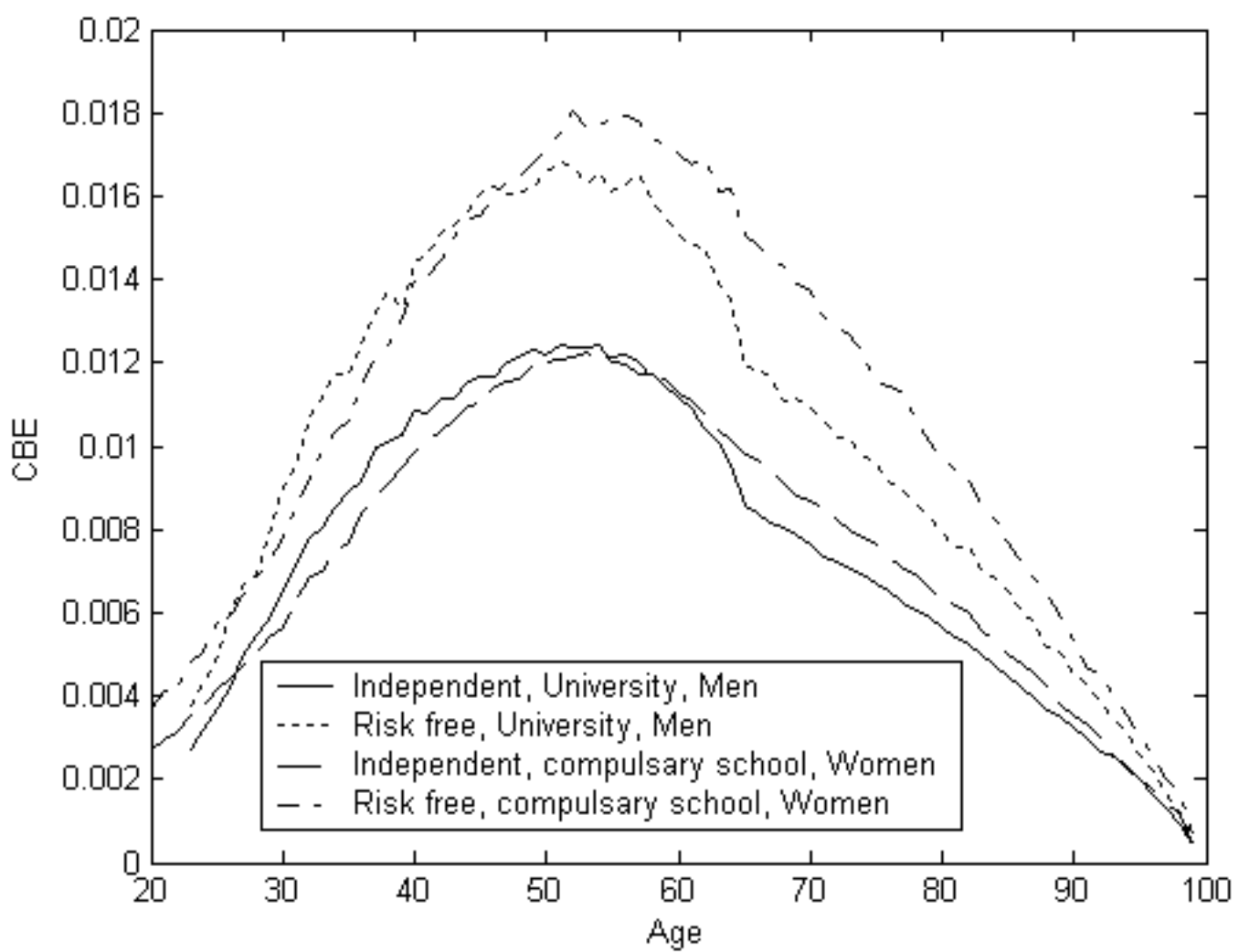

FIG. C.7 Gain in consumption and bequest equivalent units $C B E$ for the remainder of the life, due to making the NDC account independent or risk free for men with an University degree and women with compulsary school only. 

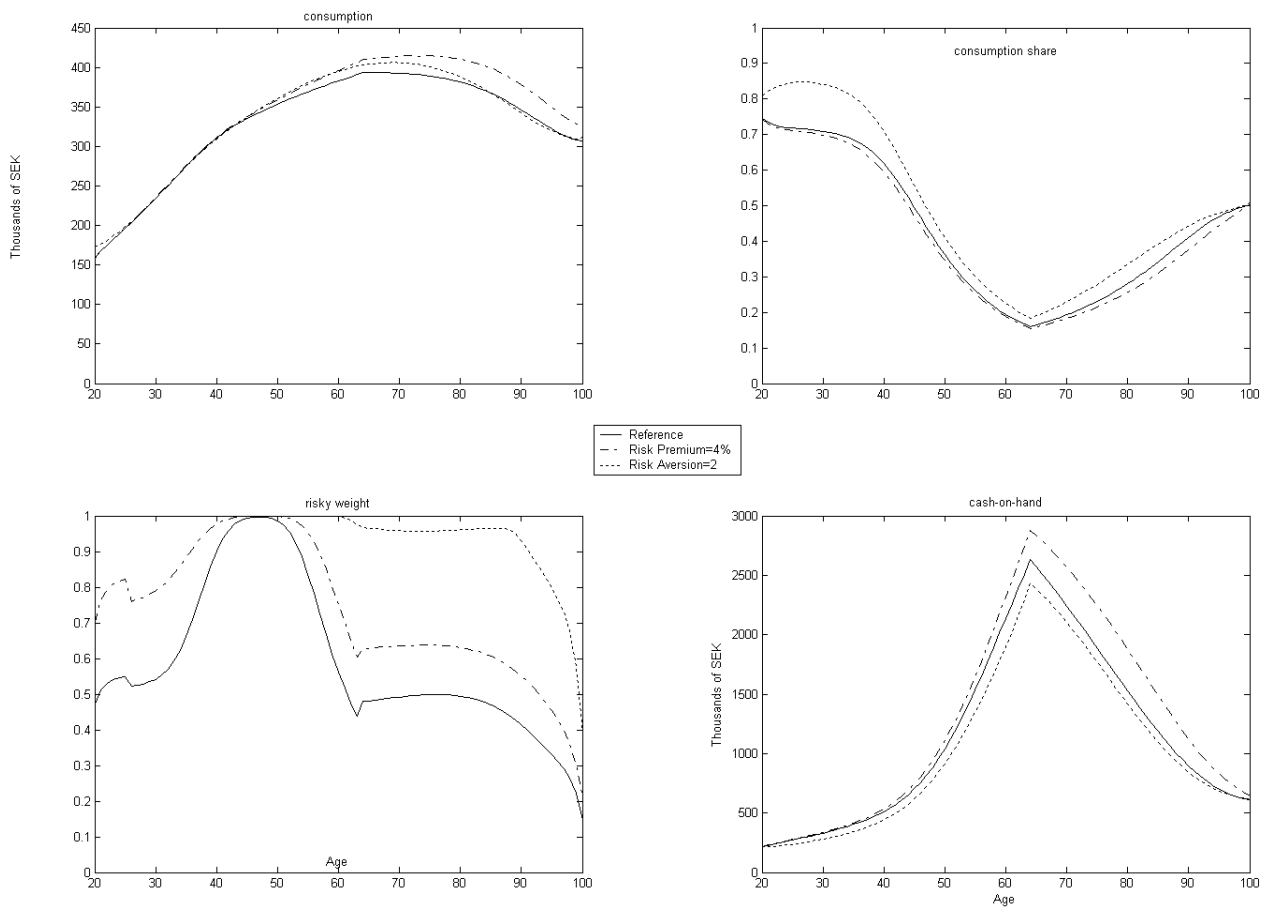

FIG. C.8 Simulated profiles for men with High School degree. Effects from changing the risk premium and relative risk aversion. 


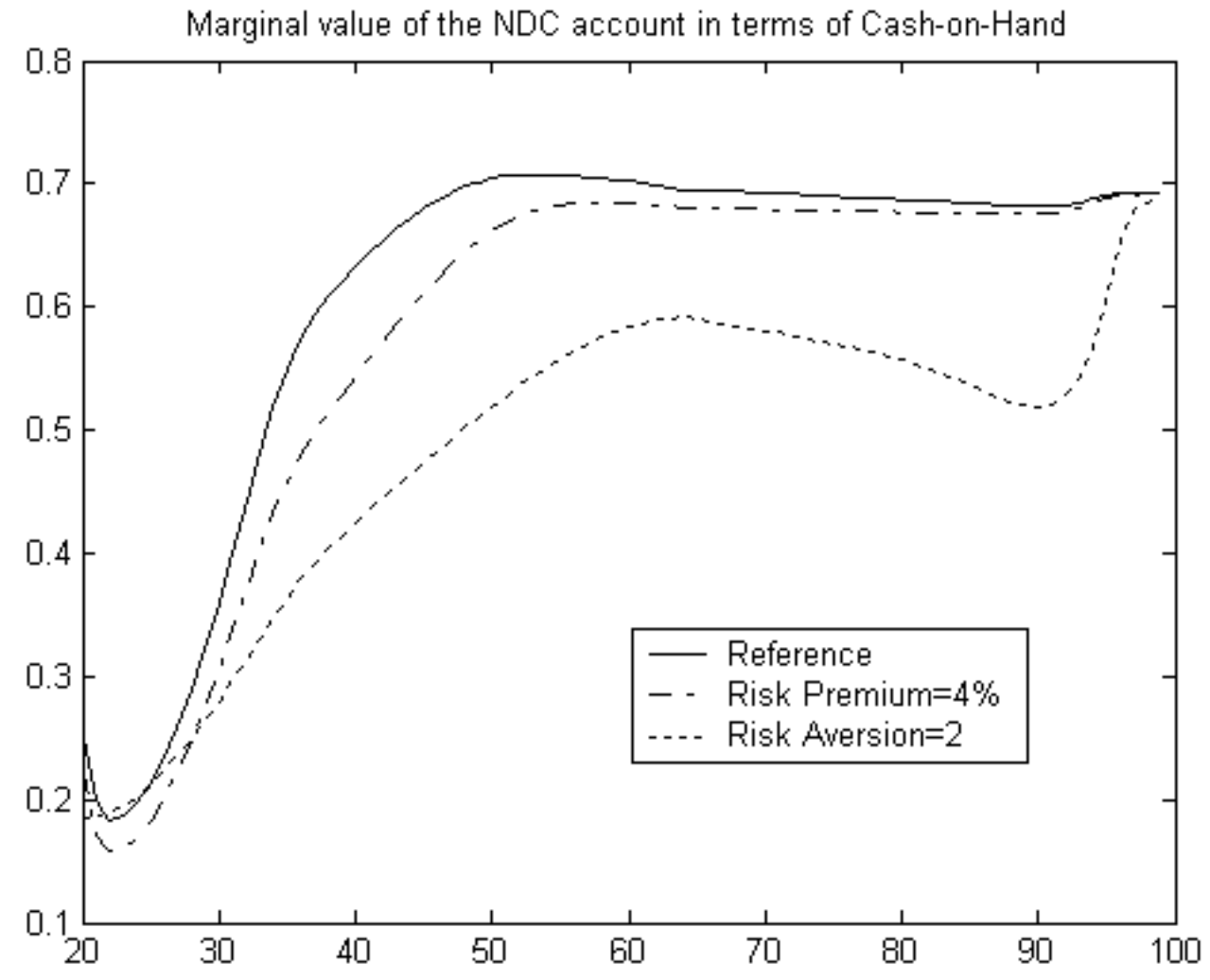

FIG. C.9 Effects on the marginal value of the NDC from changing the risk premium and risk aversion for men with High School degree. 


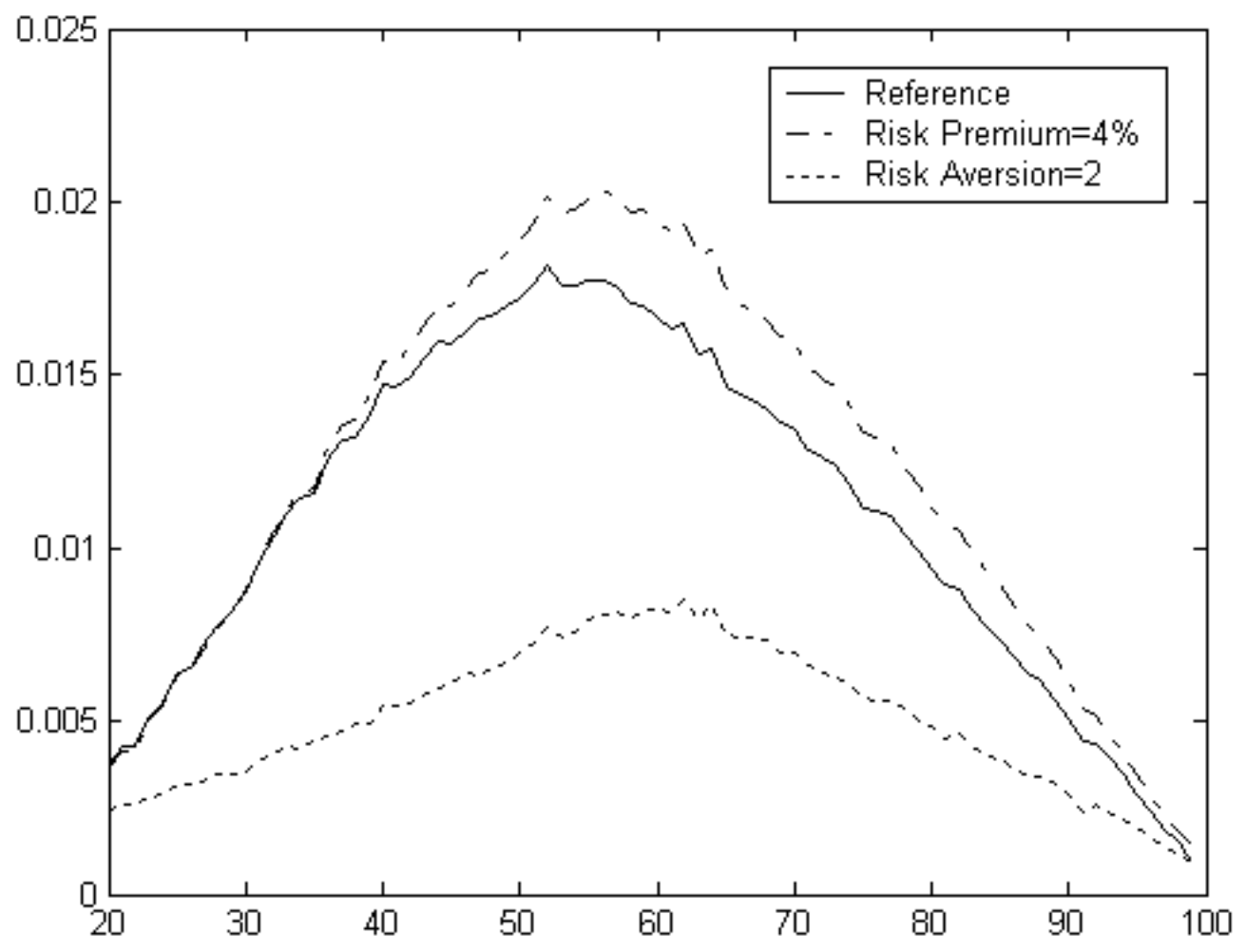

FIG. C.10 Gain in consumption and bequest equivalent units $C B E$ for the remainder of the life, due to making the $N D C$ account risk free for men with High School degree. 


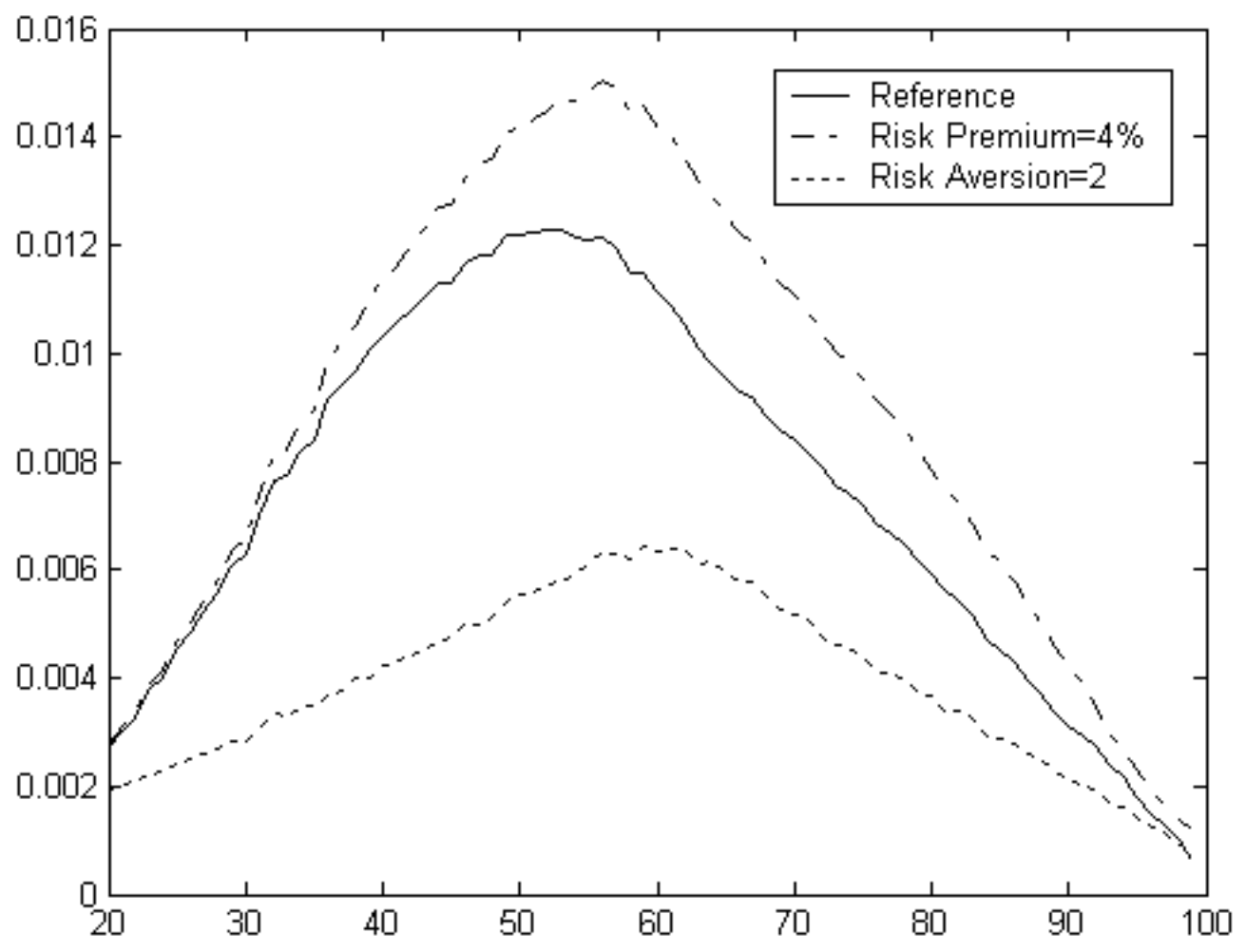

FIG. C.11 Gain in consumption and bequest equivalent units $C B E$ for the remainder of the life, due to making the $N D C$ account independent for men with High School degree. 


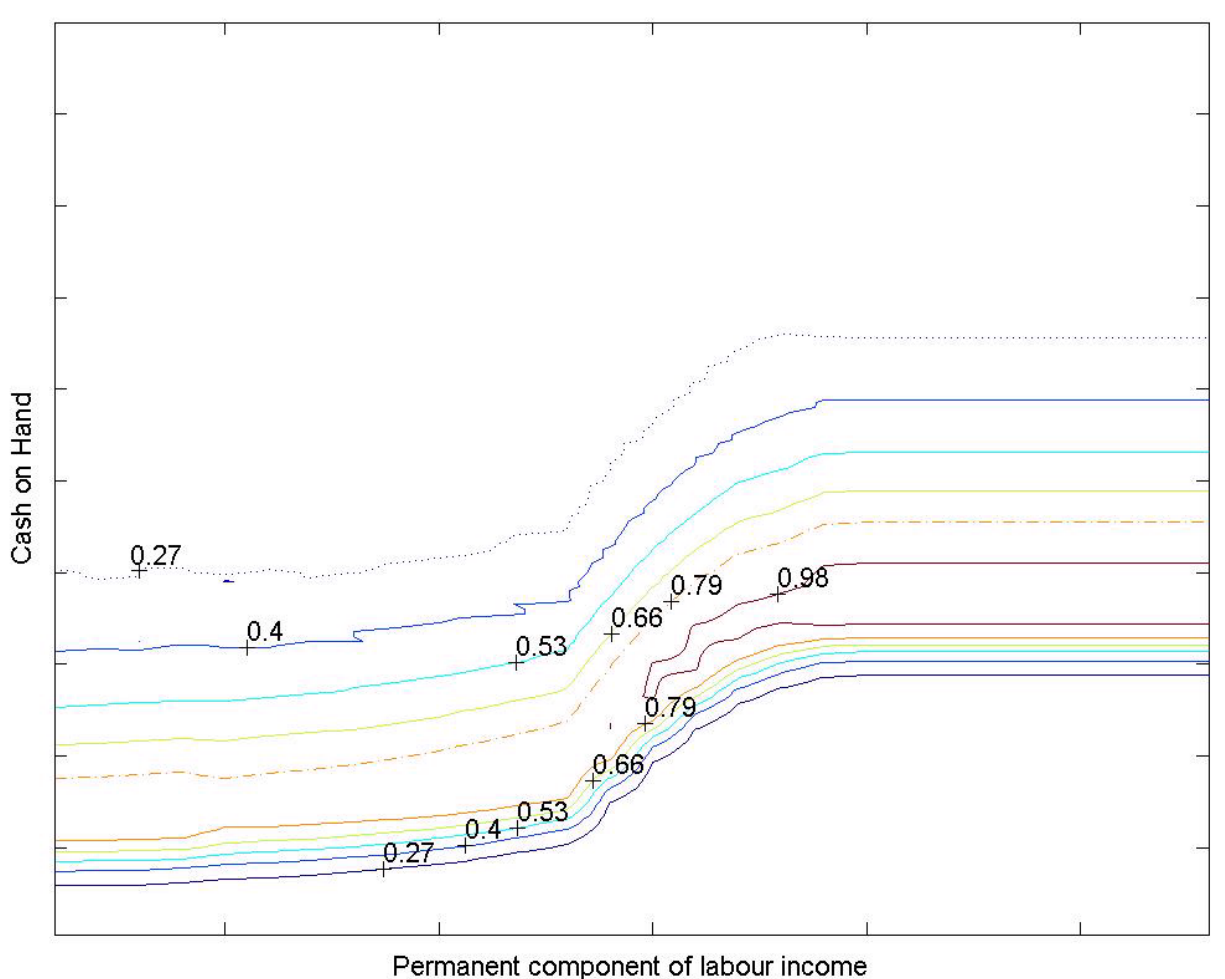

FIG. C.12 Proportion of savings allocated to the risky asset $\alpha$ at the age of 64 with $N D C$ held constant for men with High School degree. 


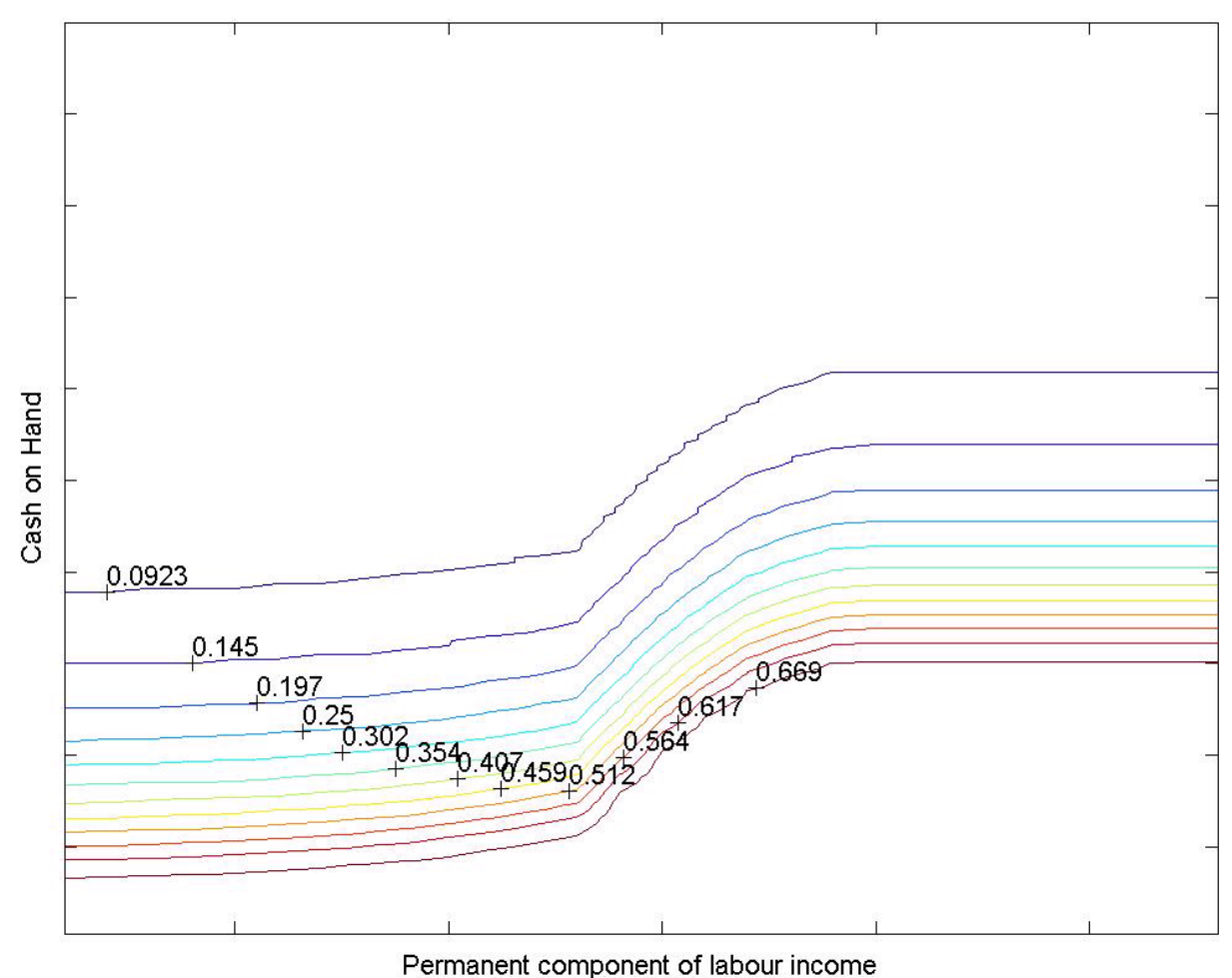

FIG. C.13 Proportion of cash on hand consumed $\theta$ at the age of 64 with $N D C$ held constant for men with High School degree. 


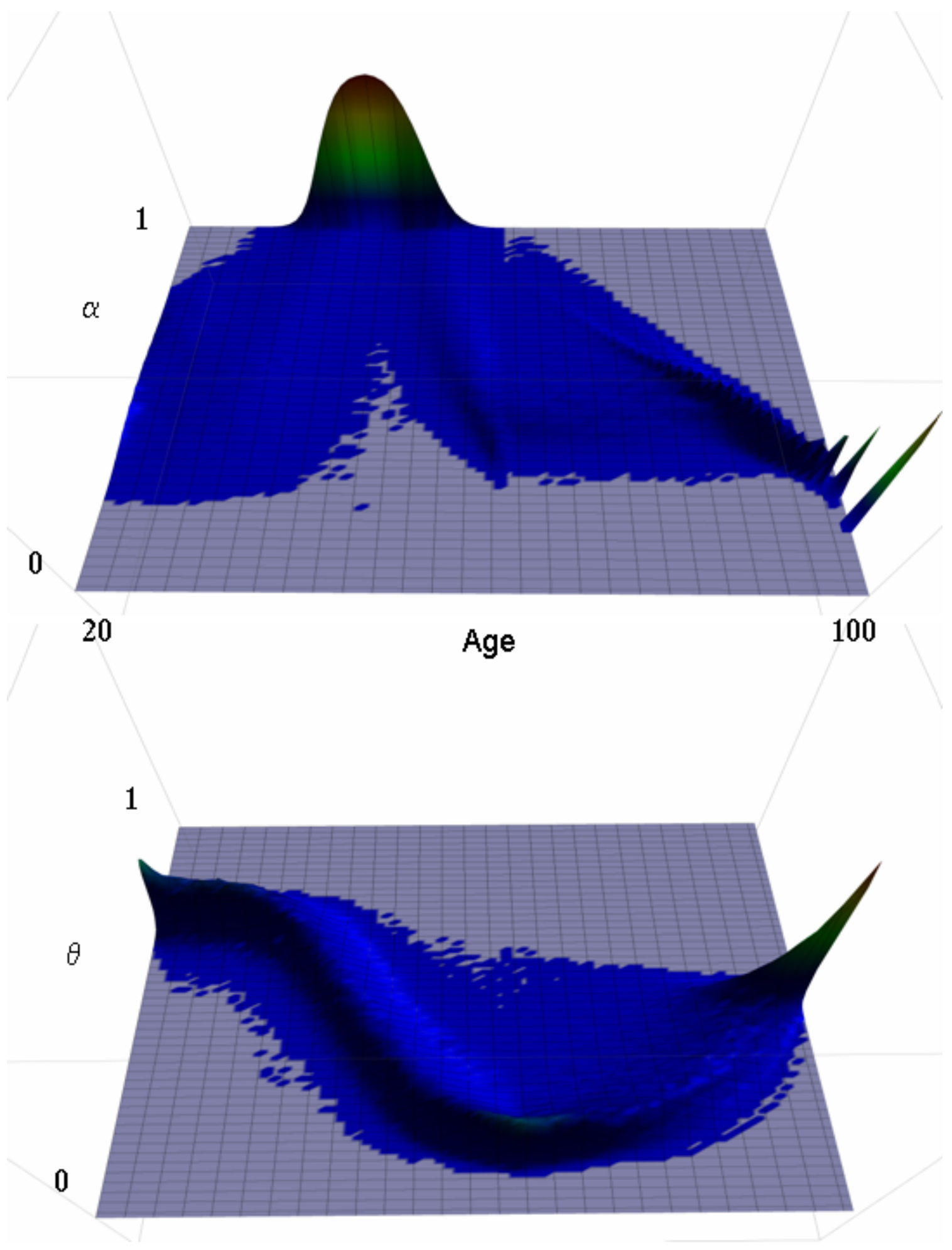

FIG. C.14 Simulated frequency distributions for the choice variables across age for men with High School degree. Upper picture is the proportion of savings allocated to the risky asset $\alpha$. Lower picture is the proportion of cash on hand consumed $\theta$. 